
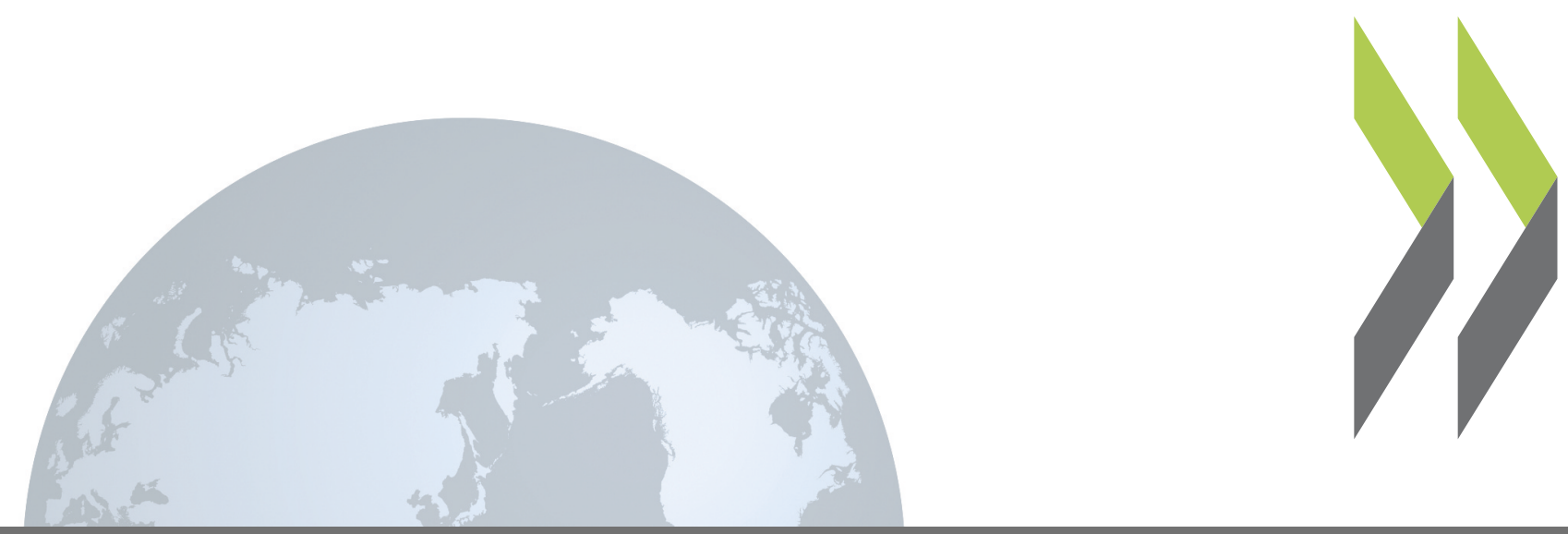

OECD Working Papers on Public Governance No. 37

The public sector innovation lifecycle: A device to assist teams and organisations in developing a more sophisticated approach to public sector innovation

OECD 


\section{The Public Sector Innovation Lifecycle}

A device to assist teams and organisations in developing a more sophisticated approach to public sector innovation 


\section{Abstract}

Innovation is at the heart of any successful enterprise; without an ability to introduce, implement and integrate new ideas, any organisation or endeavour will soon find itself overtaken by changed circumstances and external events. Through innovation, public sector organisations can engage with a changing world and the associated changing societal expectations. Innovation can help government organisations deliver or contribute to better outcomes, implement new agendas and priorities, and prepare for the unknowns of tomorrow.

Yet, the underlying ingredients for successfully integrating innovation into the core operations of a public sector organisation or team are still being identified and learnt about. The practice of innovation continually evolves, and thus so, too, do forms of the support needed to best enable and facilitate innovation.

This working paper seeks to contribute to the understanding of the public sector innovation process at an organisational or team level, and suggests areas for consideration for public sector organisations developing their innovation capabilities. It explores why a more sophisticated approach to public sector innovation is required and explains how an explicit innovation process (the innovation lifecycle) can support such an approach. The paper argues that organisations need to take a multifaceted portfolio approach, combined with a more deliberate recognition of other actors in their ecosystem. It finishes by examining how the innovation lifecycle plays out in practice, and suggests criteria to guide organisations and teams in selecting tools and methods to support them along the different stages of the innovation lifecycle.

This work brings together various strands of research conducted over the past three years by the OECD Public Governance Directorate's Observatory of Public Sector Innovation, through its Network of National Contact Points, including a synthesis of the work carried out in the framework of the H2020 Research Funding Programme.

OECD Working Papers should not be reported as representing the official views of the OECD or of its member countries. The opinions expressed and arguments employed are those of the authors.

Working Papers describe preliminary results or research in progress by the author(s) and are published to stimulate discussion on a broad range of issues on which the OECD works. Comments on Working Papers are welcomed, and may be sent to the Public Governance Directorate, OECD, 2 rue André-Pascal, 75775 Paris Cedex 16, France. 


\section{Table of contents}

Abstract $\quad 2$

1 Introduction 5

$\begin{array}{ll}\text { What determines how and to what extent innovation occurs? } & 7\end{array}$

The innovation process at the team/organisation level: the innovation lifecycle 12

Innovation lifecycle as a tool for teams and organisations $\quad 14$

A note: Innovation is a political process $\quad 14$

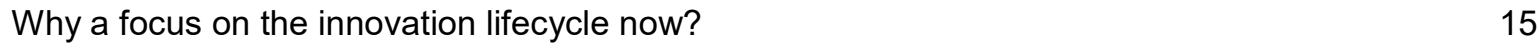

2 A changed context 16

A different context requires a different approach $\quad 17$

The changed context and the operational level $\quad 19$

The changed context and the stages of the lifecycle $\quad 20$

Innovation is a process but an uncertain one $\quad 23$

3 A multifaceted portfolio approach 24

The innovation process is stronger when complemented by a portfolio approach 25

Using the facets as prompts for the lifecycle stages $\quad 26$

Innovation takes place within a broader ecosystem $\quad 28$

4 An ecosystem perspective $\quad 29$

$\begin{array}{ll}\text { Segmenting ecosystems } & 30\end{array}$

The lifecycle as a prompt for considering ecosystem relationships 33

Public sector innovation driven from outside the public sector 33

$\begin{array}{ll}\text { The lifecycle in practice } & 34\end{array}$

5 The innovation lifecycle in practice $\quad 35$

$\begin{array}{ll}\text { Identifying problems } & 36\end{array}$

Generating ideas $\quad 39$

Developing proposals $\quad 43$

Implementing projects $\quad 48$

Evaluating projects $\quad 51$

Diffusing lessons $\quad 56$

6 Summary $\quad 60$

$\begin{array}{ll}\text { A summary } & 61\end{array}$

Innovation is about what is new to context, and therefore requires a contextual approach 62

A caveat $\quad 62$ 


\section{Tables}

Table 1.1. Public sector innovation - determinants of innovation at the individual, team/organisational and system levels

Table 2.1. The public sector operates in a new reality

Table 2.2. How a changed context affects each stage of the innovation lifecycle

\section{Figures}

Figure 1.1. Innovation lifecycle

Figure 2.1. From scarcity to abundance $\quad 18$

$\begin{array}{lr}\text { Figure 3.1. Innovation is multifaceted } & 25\end{array}$

Figure 4.1. Understanding the different segments of the ecosystem 32

Figure 5.1. Asker Welfare Lab contributes to an evident improvement of the citizen's situation 52

\section{Boxes}

Box 5.1. San Francisco Fix-It Team $\quad 36$

Box 5.2. Citizen Feedback Dashboard $\quad 37$

Box 5.3. Crowdsourcing alternative policy proposals' impacts on SMEs (small and medium enterprises) 38

Box 5.4. Portugal's Participatory Budget process 40

Box 5.5. CSIRO Idea Management System 41

Box 5.6. UNDP Positive Deviance Pilot: strategies for enhancing women's public participation in Pakistan's
Federally Administered Tribal Areas (FATA)

Box 5.7. Citizens Jury, Compulsory Third Party Insurance, Canberra, Australia 44

Box 5.8. Northern Ireland (NI) Public Sector Innovation Lab 'Hack the pain' hackathon 46

Box 5.9. Artificial Intelligence and the 'Bomb-in-a-Box' Scenario: Risk-Based Oversight by Disruptive
Technology

Box 5.10. Project Open Data (United States) $\quad 49$

Box 5.11. Portugal: LabX as a safe space for experimentation in the heart of Public Administration 49

Box 5.12. Outcome-Based Evaluation to improve services and break siloes: Asker Welfare Lab 52

Box 5.13. The Danish Innovation Barometer $\quad 53$

Box 5.14. Design Thinking and Rapid Impact Evaluation for Public Sector Innovation 55

Box 5.15. Spreading Innovation -- Denmark $\quad 56$

Box 5.16. Dealing with the triple challenge of sustainability, scale and replication: the Network of
Experimentation Labs in Portugal

Box 5.17. Cross-Government Networks to Foster Diffusion (Canada) 59 


\section{Introduction}

Innovation is vital for any team or organisation to be effective, but it cannot be relied upon to happen by luck or chance. To move beyond serendipity requires a deliberate approach. Such an intentional outlook necessitates understanding the underpinning factors that shape innovation, and how they manifest at the level of the team or organisation. This allows for innovation to be approached and engaged with as a conscious process, which allows for the practice of innovation to become more sophisticated and tailored to the context and needs of organisations. 
Innovation matters. It is at the heart of any successful enterprise. Without an ability to introduce, implement and integrate new ideas, any organisation or endeavour will soon find itself overtaken by changed circumstances and external events. Public sector innovation, "implementing something novel to context in order to achieve impact" (OECD, 2017a) is part of how public sector organisations can engage with a changing world and the associated shifts in societal expectations. A deliberate approach to innovation is a part of how government organisations can hope to do better, to deliver or contribute to better outcomes, to deliver on new agendas and priorities, and to prepare for the unknowns of tomorrow.

This matters because of the direct operations of public sector organisations, which need to be efficient and capable for their successful functioning. The public sector is also a large component of national economies, and so the innovation efforts of public sector organisations have an impact upon the broader economy. "More innovative and efficient public sector services are also important in supporting innovation in other parts of the economy and throughout society" (OECD, 2015: 218). Innovation must occur in public sector agencies so they can better achieve their missions, but also because they will shape and affect innovation in the rest of society and the economy.

The OECD, through its Observatory of Public Sector Innovation (OPSI) has witnessed innovative efforts happening in the public sector around the world. The cases of innovation range from the bold (e.g. Canada's Talent Cloud project which is rethinking how the public service manages, leverages and accesses skills) to the more modest but equally important (e.g. novel processes that make it easier for people to pay the right amount of tax on time). The public sector, sometimes with its partners from other sectors and sometimes on its own, is indeed innovating. However, as has been seen from its investigations of country studies (OECD 2018a, OECD 2019a), this innovative activity is rarely systemic, being driven more by individual efforts or responding to crises or individual organisational needs. There are compelling reasons that more innovation is needed within the public sector, including that citizens expect and demand that their governments do better and deliver better outcomes.

Yet, as with many other core corporate functions, innovation is easier said than done. The act of innovation inherently involves questioning the status quo. It also involves uncertainty, as the intrinsic novelty means there is no guarantee about what will happen or how it will happen. Both of these qualities can make for an unattractive value proposition for undertaking innovative activity. Often then, given established practices, existing investments and processes, it can be difficult to find the time, resources and will to consider and pursue new ways of doing things, especially when there is no promise that the new thing will be better than the old one. "Why fix what is not broken?" can be a powerful sentiment when there are pressing responsibilities and immediate priorities that need to be attended to now. The potential needs of tomorrow are rarely as resonant as the very apparent and pressing tasks of today.

However, the costs of waiting until something breaks before innovating can be great. Innovating in response to a crisis may work - it is easier, after all, to overcome reluctance or barriers to innovate when there is a clear 'burning platform' - but it is rarely ideal, inexpensive or easy. Anything that is new will take time to perfect, not least because doing new things or doing things differently necessitates learning, practice and investment. No entirely new thing can be introduced perfectly. This is problematic for the public sector though, as public sector agencies rarely have the luxury of being able to introduce things that are not ready. Citizens, let alone politicians, rightfully expect the operations of government to be dependable. Governments need to have some confidence that what is being tried or introduced will work as hoped, or, at the very least, that it is the best of what is on offer if the circumstances require immediate action.

Therefore there is an uncomfortable tension to public sector innovation - simultaneous needs for new things and for due care. This requires innovation in the public sector to be an ongoing and deliberate, rather than sporadic and reactive, activity. When supported appropriately, innovation can aid in addressing the things that are already broken as well as preparing for the things that are yet to break. Public sector innovation can assist in addressing existing, evolving and emergent challenges and issues as well as to 
prepare for those yet to come. But it cannot do so if it is left to the last minute or relegated to the side. Government cannot wait to innovate, not if it is to innovate either responsibly or regularly.

Innovation, though, is difficult to undertake successfully, let alone when considered through the lens of public sector bureaucracy, which has, in many ways, been designed to limit variation and experimentation. For instance, governments have often prized equal treatment and predictable, even if suboptimal, outcomes over differing results delivered by differing strategies. It is necessary to recognise and appreciate the institutional context, even if not wanting to be limited by it. If innovation is to occur on an ongoing basis across the public sector, relying on a need for innovation alone will not be enough to ensure innovative activity will occur. Innovation must be explicitly recognised and supported, otherwise it will be reliant upon some mix of exceptional individuals, crises and luck in order to overcome the institutional default settings that favour dependability and what is known. The latter strategy will never be a recipe that can be depended upon to provide consistent results. Innovation must move from an incidental, serendipitous activity, to a process that is deliberate and routine.

This report provides some insight into the innovation process as it occurs at an organisational or team level, and some of the key considerations for public sector organisations. It builds upon work done by the OECD with the funding support of the European Union's Horizon 2020 research and innovation programme (under grant agreement No. 671526) but also incorporates other work by the OECD's Observatory of Public Sector Innovation about how to support innovation as a systemic activity. The report complements the work contained in Fostering Innovation in the Public Sector (OECD 2017a), which examined the core functions needed to support innovation, by examining the underlying factors that shape whether and how innovation occurs at a team or organisational level. It is an addition to the ongoing development of theory and guidance around taking a more deliberate and sophisticated approach to public sector innovation.

\section{What determines how and to what extent innovation occurs?}

In order to appreciate innovation as a structured process that can be replicated and supported, it is first necessary to understand what actually shapes how and to what extent innovation will occur. i.e. in order to foster the process, it is first necessary to understand what shapes it.

What, then, determines whether innovative activity will occur? In the study of the innovation system of the Public Service of Canada (OECD, 2018a), OPSI identified four determinants, four underlying factors that affect the likelihood of innovation taking place. Innovation will not take place in a consistent, systematic or systemic fashion if there is no reason, no possibility, no capability, and no experience that reinforces it.

- Reason: innovation challenges established practices and calls into question existing ways of doing things. However, existing measures are often likely to win-out over innovative ones unless there is a good or compelling reason for innovation to occur (e.g. current practices are no longer delivering results or better options have become available). Without a full appreciation of the reason for innovation to take place, established reasons acting against innovation will normally dominate.

- Possibility: at any moment there may be a range of options that are given serious consideration by decision-makers. What are the things that will be chosen, resourced and prioritised? Innovative initiatives are new, and thus imperfect as they have yet to benefit from the time, practice, track record and investment that more established initiatives have already had. This comparison places them at a distinct disadvantage to already established options when assessed by traditional decision-making processes. Existing alternatives are already understood to some extent - there is evidence, of some form, about how and when (and possibly why) they work. On the other hand, innovative options are not (and cannot) be well understood, as they are new to the context and thus uncertain with the associated risk of being surprising, a quality rarely sought after or desired by decision-makers. Therefore, without some form of added impetus or weighting, without something or some action that creates a possibility for innovation to take place (e.g. a focus on 
how current approaches are failing), decision-making is likely to preference, or default to, existing options (with their associated inertia from having an evidence-base, previous investment and commitments).

- Capability: doing things differently or doing different things will often require new and different capabilities to those used required by existing practices. Yet the capabilities for established activities are likely to more developed and sophisticated by their virtue of already existing and thus already being practiced, resourced and understood. Innovation, as an activity, will therefore be at a disadvantage to established activities without added attention to, or support for, the question of capability. Why would decision-makers preference an alternative where there are not existing skills, processes, infrastructure and systems suitable for the task?

- Experience: established activities are, inevitably, recognised or accepted to some degree as part of business-as-usual, whereas innovative initiatives being new may be regarded with scepticism or even experience pushback, thereby weakening the inclination to continue for those advocating the innovative activity. Therefore, innovative activity will often be at a disadvantage to existing activity unless there is some positive experience or feedback that provides sufficient justification to keep attempting something new. This might take the form of an evaluation, evidence that the innovation is working as needed, or it might be as simple as encouragement and positive feedback from clients or management. Equally, negative feedback is likely to weaken any motivation or momentum for pushing against the status quo and contribute to difficulties in creating allies or momentum behind the initiative. Unless innovative activity is reinforced or made to feel part of normal practice, then default settings will generally erode the momentum behind doing something differently to standard practice.

Simply put, these determinants help to illustrate the factors that shape whether and to what extent new things will be attempted. Without a reason, the possibility, the capability and the experience that reinforces it, innovation (as a process or a project) is, all other things being equal, likely to lose out to the status quo. Every system has a degree of inertia - exacerbated or magnified by the culture, traditions, protocols, processes, knowledge and evidence bases, previous decisions, investments and commitments - that will limit innovation (as a project or in regards to specific projects/initiatives). This limiting element is a necessary part of having a relatively stable and dependable system, but it can often limit more than intended or desired. The determinants and the extent to which they are in force, help to consider whether innovation will only happen irregularly, such as in crisis situations (when default settings can lose some of their pertinence) or more regularly.

Each of the determinants manifest differently depending on the level of activity at which they are to be examined. For instance, innovating as an individual is different to innovating as part of a broader team or organisation, which in turn is different to when innovation is undertaken as a systemic activity. One person attempting something different in their job is different to an organisation introducing a new approach which is different to the whole of the public sector adopting a new way of working. The determinants take on different attributes and play out differently at each level (based on OECD, 2019a, 2018a).

- Reason - what is driving the intent to innovate?

- At the individual level, the reason for innovation relates to the motivations of the individual. Why do they feel it is necessary or desirable to try something different? What prompts them to question, or go against, the status quo? Without such motivation, it will generally be easier (and therefore more likely) for someone to follow existing practices.

- At the team or organisational level, when there are multiple people involved, motivations still matter, but multiple people working together are rarely likely to have exactly the same motivations as each other. Instead, in order for there to be a galvanising reason to attempt something different, there needs to be a shared sense of a problem that requires innovation (e.g. a specific government priority, trying to improve upon what exists, or responding to citizen 
feedback about a service) or an identified idea or opportunity (e.g. a new technology promises better ways of working). Without this, other organisational or team responsibilities (or individual motivations) will likely prevail.

- At the systemic level, a specific problem or an identified opportunity will rarely be sufficient to motivate coordinated efforts. For any government priority (e.g. reducing energy emissions), there will be different perspectives and priorities (e.g. the transport ministry will have solutions and suggestions different to those of the environment ministry). There may be competing or conflicting approaches or confusion over respective responsibilities. At the system level there needs to be clarity: a clear signal for public servants and stakeholders about innovation, including what it is, why it matters and how it fits with other priorities. Without this clarity, the inherent ambiguity of innovation will tend to mean other, clearer agendas will dominate.

- Possibility - what affects the likelihood of innovation being attempted?

- At the individual level, the possibility of innovation relates to whether the individual has the opportunity to try something different. Do they have a chance to innovate, to try something different? Will they be listened to and their proposals considered legitimate? Without such an opportunity, it will not matter if they are motivated to do something differently, for they will not be able to meaningfully act upon that desire.

- At the team or organisational level, opportunities need to be coordinated if there is to be a collective effort. Five (or fifty) people may have an opportunity to innovate, but unless the opportunities are coordinated, they are unlikely to progress very far, particularly if they all take advantage of all of their respective opportunities at once but, some leading in very different directions). Thus, possibility at this level relates to whether there are ideas that are to be pursued or proposals developed that provide a means for multiple people to collectively and constructively try something different. Without specific ideas or proposals connected to priorities, any push for innovation is likely to lose momentum or be lost amongst competing efforts.

- At the systemic level, one single specific idea or developed proposal will rarely be sufficient to drive innovative efforts across different organisations or sectors towards collective goals. The opportunity to innovate will rather be shaped by the extent to which there exists parity between innovation and existing options. Default settings - institutional, process, budgetary, etc. - will generally preference the status quo, as that is what is already known and resourced. Without additional weighting, innovative options will, more often than not, be at a disadvantage to existing options because of the bias and inertia towards established courses of action. Otherwise, innovation will only occur in situations where the default settings have been perturbed in some way, such as a crisis, where the current state is no longer satisfying needs and requirements and thus providing a situation where new options are given more credence.

- Capability - what is needed in order to carry out the attempt at innovation?

- At an individual level, the capability for innovation relates to whether the person(s) attempting an innovative effort actually has the abilities to do so. If someone does not have the skills, nor the necessary tools and resources to do so, to attempt and carry out a novel initiative, then they are unlikely to get very far in their innovative endeavour.

- At the team or organisational level, carrying out the project will require not just different abilities, but processes and supporting processes to coordinate their use. A range of people, skills and approaches will need to be brought together. Different constellations of skills, resources, tools, processes and support structures may be needed for different types of innovative projects. This is about project implementation. Without effective project implementation, initiatives will falter, given their inherent uncertainty and difficulty. 
- At the systemic level, capability relates to the project implementation of multiple organisations, sectors and partners or stakeholders, and is thus about the suitability of infrastructure, investment and commitment for new ventures. System capabilities will often reflect and cater to what is already being done (e.g. IT systems will be designed for existing projects), and thus innovation as an activity will be hindered unless there is explicit attention to the suitability for new approaches. At the system level there are also often moves towards ensuring coherence, and potentially standardisation, as deviation from the standard adds complexity and overheads. Yet without suitable capabilities - often new capabilities that support new and different ways of doing things - system-level innovation will struggle to emerge, let alone thrive.

- Experience - what affects whether innovation continues?

- At an individual level, the experience of innovation can be seen in learning from what happens. An individual attempting a new way of working will learn whether it results in better outcomes, whether it fits with their roles and responsibilities or whether it supports their identity and selfperception. A negative learning experience, where the process of innovation feels deeply uncomfortable, upsetting or disappointing, will likely reduce the motivation for further innovation. Whereas a positive learning experience, one where even if the specific innovation activity does not lead to success but is accompanied by learning and a joy of discovery or insight, might lead to the opposite.

- At the team or organisational level, there will be learning from multiple people and perspectives, and this will need to be made explicit if it is to effectively inform future efforts. Experience at this level takes the form of evaluation and the diffusion of lessons. Without this, innovative activities, with uncertain outcomes and steep learning curves will more often be seen as costs rather than investments, thereby reducing the appetite for further innovation.

- At the system level, with multiple organisations and actors, experience is about what is seen as 'normal'. Normality determines what is integrated into the day-to-day and seen as expected or usual, and what is seen as a frolic and unusual (and therefore dubious). As innovation inherently involves novelty, a practice of innovation will often seem or feel abnormal, rather than a part of what feels normal, unless it is emphasised, encouraged and reinforced. Without a sense of normality for innovation, it will likely occur only within specific contexts and projects.

Table 1.1 captures the different manifestations of the determinants of innovation for the three levels of activity. 
Table 1.1. Public sector innovation - determinants of innovation at the individual, team/organisational and system levels

\begin{tabular}{|c|c|c|c|}
\hline $\begin{array}{l}\text { What level of analysis is the focus? } \\
\text { Core determinants of innovation }\end{array}$ & Individual (individual effort) & Team/Organisation (collective/shared effort) & $\begin{array}{l}\text { System (intersection and aggregate of multiple } \\
\text { efforts) }\end{array}$ \\
\hline $\begin{array}{l}\text { Reason for innovation: } \\
\text { What is driving the intent to innovate? }\end{array}$ & $\begin{array}{l}\text { Motivation to innovate } \\
\text { (e.g. I need to or want to solve a problem / try } \\
\text { something new; stand out from the } \\
\text { crowd/differentiate myself from others; do it as part } \\
\text { of my job/role/identity) }\end{array}$ & $\begin{array}{l}\text { Problem identification/ldeas generated } \\
\text { (e.g. we have to or want to fix policy or service } \\
\text { delivery challenges; respond to crises or political } \\
\text { priorities; meet stakeholder expectations; } \\
\text { achieve/work towards a mission) }\end{array}$ & $\begin{array}{l}\text { Clarity about innovation } \\
\text { (e.g. it is clear that things need to change; } \\
\text { innovation makes sense and is a priority; } \\
\text { innovation is a responsibility) }\end{array}$ \\
\hline $\begin{array}{l}\text { Possibility of innovation: } \\
\text { What affects the likelihood of innovation being } \\
\text { attempted? }\end{array}$ & $\begin{array}{l}\text { Opportunity to innovate } \\
\text { (e.g. I can work on a project where innovation is } \\
\text { appropriate or wanted; apply a new technique or } \\
\text { approach in my work; try, or to be exposed to, } \\
\text { something different) }\end{array}$ & $\begin{array}{l}\text { Ideas generated/Proposals developed } \\
\text { (e.g. we have identified options for how we might } \\
\text { solve a problem in an innovative way; processes } \\
\text { are open to doing things differently; approval exists } \\
\text { for trying something differently where appropriate) }\end{array}$ & $\begin{array}{l}\text { Parity of innovation } \\
\text { (e.g. default settings can either be challenged, or } \\
\text { are open to doing things differently; system-wide } \\
\text { rules or processes do not unfairly bias against } \\
\text { innovative proposals) }\end{array}$ \\
\hline $\begin{array}{l}\text { Capability for innovation: } \\
\text { What is needed in order to carry out the attempt at } \\
\text { innovation? }\end{array}$ & $\begin{array}{l}\text { Ability to innovate } \\
\text { (e.g. I have the tools, skills and resources to } \\
\text { undertake the innovation) }\end{array}$ & $\begin{array}{l}\text { Project implementation } \\
\text { (e.g. we have what we need to undertake the } \\
\text { project(s), including the relevant skills, systems, } \\
\text { technologies and resources) }\end{array}$ & $\begin{array}{l}\text { Suitability for innovation } \\
\text { (e.g. the infrastructure, investment, and } \\
\text { commitment exist to ensure that general systems } \\
\text { are suitable for innovative endeavours, even when } \\
\text { they may not have been anticipated) }\end{array}$ \\
\hline $\begin{array}{l}\text { Experience of innovation: } \\
\text { What affects whether innovation continues? }\end{array}$ & $\begin{array}{l}\text { Learning from innovation } \\
\text { (e.g. I learn about how people and things react, } \\
\text { what it's possible to achieve/impact, and whether } \\
\text { that change is valued) }\end{array}$ & $\begin{array}{l}\text { Evaluation/Lessons diffused } \\
\text { (e.g. we know what effects occurred as a result of } \\
\text { the innovation and have used this knowledge to } \\
\text { inform other projects; this helps shape the } \\
\text { organisation's culture and attitude about } \\
\text { innovation) }\end{array}$ & $\begin{array}{l}\text { Normality around innovation } \\
\text { (e.g. innovation is not seen as an aberration, an } \\
\text { oddity or a frolic, but rather as something that is } \\
\text { integrated and built upon) }\end{array}$ \\
\hline
\end{tabular}


In reality, activity at all of these levels is interconnected. Individuals will struggle to maintain their motivation if the organisation they are within does not recognise that there are issues where innovative approaches are needed, or if the broader system the organisation is located within is effectively signalling that changing from the status quo is low on the list of priorities. However, while each of these levels of analysis are interdependent and inter-related, the purpose of this report is to aid in advising public sector teams and organisations on their innovation process(es). The innovation lifecycle helps to provide a means to consider and engage with the different stages of the innovation process, and to consider how or if they are supporting it sufficiently for their needs.

\section{The innovation process at the team/organisation level: the innovation lifecycle}

Figure 1.1 presents the innovation lifecycle as discrete states, While the innovation process is rarely linear, the figure helps to illustrate how each of the stages contributes a different element to the innovation process, as well as the notional order in which things will often progress and how each stage shapes and affects the stage following it. More, for instance, will be learnt about the nature of the problem across the other stages. Equally, evaluation may commence in some form at the start of a project, rather than waiting until after implementation. Nonetheless, each stage reflects different issues and different factors that a team or organisation should be aware or considerate of, and the model allows for reflection on each part individually.

Figure 1.1. Innovation lifecycle

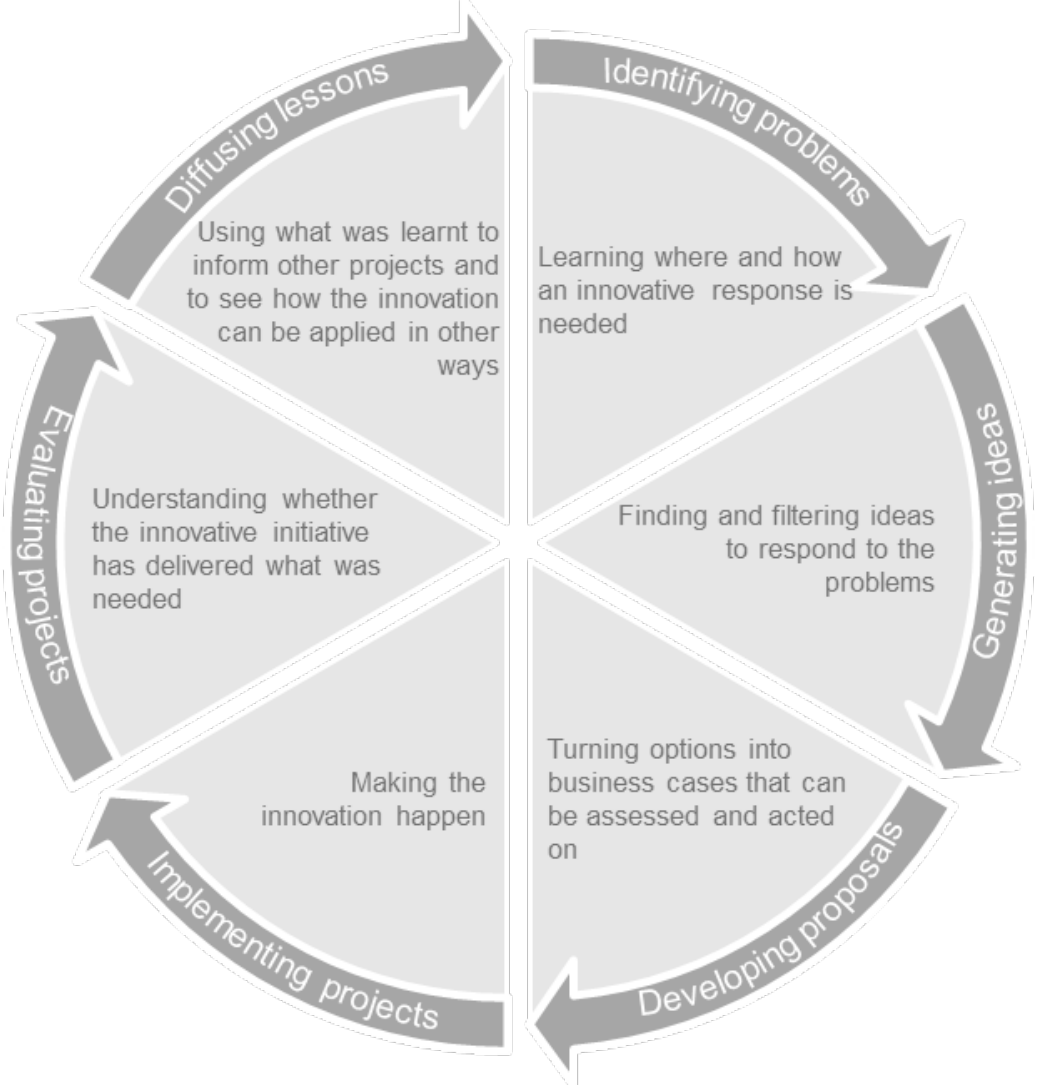

Source: OECD, 2016. 


\section{Identifying problems:}

Identifying problems is about learning where and how an innovative response is required. This learning does not only relate to existing or established problems, but also emerging problems or those yet to occur, but which will take preparation. Without exploration or a developed ability to learn about, and thereby recognise, the need for innovation, innovative activity will struggle to occur as existing activities, having their own inertia, will be focussed on instead. An organisation (or team) that is capable of continual learning and reflection, will be better able to sense the need (and the opportunities) for change, and make space for new things amidst or besides the existing activities.

\section{Generating ideas:}

Idea generation is about finding and filtering ideas to respond to the problems to provide options. An idea is an articulation of an alternative possibility (OECD, 2017b). It can reflect new knowledge and new technology, which opens the way for new ways of acting, or it can reflect new understanding of the existing world. Without the ability to effectively source ideas, a team (or organisation) will be limited in the scope of possibilities that they are aware of, meaning that they may miss out on important opportunities, or be pushed in certain directions despite the potential for better alternatives.

\section{Developing proposals:}

Developing proposals involves turning options - which may be rough and untested - into business cases that can be assessed and acted upon. This involves maturing the options selected so as more can be learnt about their relative merits and what might be entailed in their implementation, so that an informed choice can be made. A good proposal will help the relevant decision-makers (who may sometimes be the project proponents themselves) understand the costs and benefits of pursuing a course of action, and the costs and benefits of not pursuing a course of action, while not over-promising given the inherent uncertainties involved in doing something new or differently.

\section{Implementing projects:}

The implementing projects part of the lifecycle is about making the innovation real. It is about realising the objectives of the chosen proposal, while also navigating and handling the inevitable issues that arise as the idea meets reality. Project implementation makes the difference between a grand plan and a meaningful outcome. Implementation is particularly tricky for innovative projects, as innovation involves uncertainty and the chance that things may go wrong or in unexpected directions. Good project implementation will ensure that the key objectives and parameters of a proposal are met without being rigid or unable to adjust as new information is learnt from the implementation process.

\section{Evaluating projects:}

Evaluating projects is about understanding whether the innovative initiative has delivered what was needed, and why it did or did not. An innovative project may take unexpected paths, and therefore a strict assessment that only accounts for "Did it do what it said it would do?" will inhibit the necessary learning and inevitably provide an unfair account of the innovation process. Evaluation can vary in extent, range and form, but has been defined as the "systematic and objective assessment of an on-going or completed project, programme or policy, its design, implementation and results" (OECD, 2011 in OECD, 2018c). For a team or organisation, evaluation can be the difference between having a success and being successful, for without formally understanding why projects have succeeded (or failed) it will be difficult to replicate them or to repeat them. This issue is exacerbated when it comes to innovation, as the inherent uncertainty 
involved can make it difficult to identify causal relationships, necessary preconditions and contributing factors.

\section{Diffusing lessons:}

The diffusing lessons stage is about using what was learnt to inform other projects and to see how the innovation can be applied in other ways. Innovation is an inherently wasteful process (Potts, 2009), and the costs of attempting and undertaking experiments can be high, especially if viewed at the level of a single project that failed to deliver expected results. Diffusing lessons can help ameliorate some of the costs, as well as ensuring that innovation successes can be learnt from, scaled up or adapted as appropriate.

\section{Innovation lifecycle as a tool for teams and organisations}

As noted, each lifecycle stage is not truly distinct - each affects the others, and each is of relevance throughout a project or thinking about innovation as a process more generally. If no thought is given to evaluation when the need for innovation is considered, then the ability to assess success (or failure) will be limited. If consideration of the nature of the problem that requires an innovative response only occurs at the beginning of the process, then insights into the nature of the problem that could be gained from testing ideas and implementing them will be missed.

However, from a team or organisational perspective, the lifecycle helps to understand the constituent parts or ingredients and to consider how or if the necessary support for an effective innovation process is being provided. It is also important to note that the results of the process - the overall quality of the outcomes will be determined by the weakest part of the process. Poor ideas (and a poor ability to find and filter ideas more broadly), will lead to a poor result, no matter how skilled the implementation. A poor proposal (and a poor ability to convert options into business cases) will see the best ideas lose to a less good idea that is sold better. Poor implementation may ensure that a promising proposal is consigned to history as a regretted mistake. Each part is necessary to the success of the whole.

Therefore, the lifecycle is a means for teams and organisations to consider their innovation process, their strengths and weaknesses, what they need innovation for, and how they are supporting it. If innovation is not treated as an explicit process, when it happens it will be predominantly shaped by other processes, by individual passions, external events or systemic forces rather than need, intent or good governance. In such cases, the team or organisation will be reactive, rather than shaping innovation purposefully for their context and needs.

\section{A note: Innovation is a political process}

Innovation is about changing the status quo, and can be unpredictable. It is a process that is, therefore, to some extent uncontrollable, as the impacts and flow-on effects are unknowable and hard to manage or govern. By changing the current state, innovation will inevitably create beneficiaries and, quite often, losers. Two things, then, are true: 1) Public sector innovation is an uncomfortable activity in a public/civil service context where there is the general expectation and requirement to be apolitical; 2) Innovation is inherently political, because it can change who wins and loses.

A hypothetical example can help to illustrate this political dimension. Take the case of a national government commencing digital transformation work for its taxation agency. The new digital tax process links with banks and employers and automatically takes information from them and a range of other sources, thereby only requiring taxpayers to verify information rather than entering it themselves. The system also links a variety of government benefit entitlements and automatically assesses eligibility. This 
innovative work is seen as a success, with the tax process being widely welcomed and a significant productivity enhancement. However, tax agents and accountants suddenly find themselves with a large reduction in their work, as fewer people now require their services. There is pushback and lobbying from the industry, and the tax agency is ordered to consult with the industry to see what could be done. While the possible benefits are great, they are diffuse with many people seeing little improvement, whereas the losses are highly tangible for a very specific and, in this case, vocal population.

This hypothetical provides a sense of the political issues: even where an innovative project may seem at the outset a clear and uncontroversial (and thus notionally apolitical) good, there may be unintended or initially unrecognised flow-on effects that create losers - in this case, losers that could be more visible and louder as political agents than the winners, who may not be as invested in the issue.

Innovation is thus a political process. It shapes what is possible, what is expected and what is desirable. It is about shifting between different futures.

Traditionally, the political level was meant to be responsible for approving or endorsing decisions with a political dimension. However, as innovative activity becomes more decentralised, and as it is needed on a more consistent basis, this becomes impossible. If an approach of "let 1000 flowers bloom" is taken, then no minister of state will have time to carefully pick the nicest bloom. Given this, it is even more important that innovation be a deliberate and explicit activity, so the political nature can be recognised and governed as appropriate for the particular context.

\section{Why a focus on the innovation lifecycle now?}

The next chapter explores why a changed context means an explicit focus on the innovation process is of benefit. 


\section{A changed context}

Governments have always innovated, but they now operate in a context of greater uncertainty and increased possibilities. This changed context necessitates a more sophisticated approach to the innovation lifecycle and each of its stages. 


\section{A different context requires a different approach}

The different stages of the innovation lifecycle are all things public sector organisations have had to do as part of their traditional work. None of these are new functions - governments have always had to identify problems, develop ideas, put forward proposals, implement them, evaluate them, and then use the lessons and insights to inform further work and action. It is reasonable to therefore ask, "Why now? What is different that means public sector teams and organisations need to pay additional attention to the innovation process now?"

In part, this is because innovation has not generally been treated systematically at the system-wide level (e.g. the whole of the public sector). As the OECD (2019a) has found, innovation has often been a byproduct rather than a central focus in public administration. For much of human history this has sufficed. Governments, themselves a mix of historical innovations, have adapted and changed over time to deal with changed circumstances. However, the context has now changed fundamentally - governments currently operate in an unprecedented context of volatility, uncertainty, complexity and ambiguity (VUCA), where there is increasing technological change, and significant social, demographic, economic and environmental shifts. These factors mean that many status quo options or solutions are increasingly shortlived or in need of questioning, as they are no longer suited to the environment they are in. Therefore, while governments have always been innovating, a more sophisticated approach is increasingly warranted, with additional attention, investment and support.

This need for a more systematic and sophisticated approach was acknowledged in the OECD Declaration on Public Sector Innovation (2019b), through which participating countries affirmed their support for innovation and committed to:

- Embrace and enhance innovation within the public sector

- Encourage and equip all public servants to innovate

- Cultivate new partnerships and involve different voices

- Support exploration, iteration and testing

- Diffuse lessons and share practices.

But how do these general forces of change relate to individual teams and organisations? What do these broader global shifts mean to a team on the ground trying to do better work?

To understand this, it is useful to look at what is underpinning the changed context (OECD, 2016). While there are many underlying factors, perhaps the one that has the most significant relevance to both government and to the innovation process is the shift from little/scarcity of information to relative abundance of information (drawing on the work of Hagel, Brown and Davison, 2010; Diamandis and Kotler, 2012; Ismail, Malone and Geest, 2014). For instance, the change in the amount and availability of innovation can be seen in its manifestation in terms of:

- Data availability: the world has experienced a vast increase in the availability and accessibility of data. This growth is likely to continue and even increase with the advent of the Internet of Things and a proliferation of varying types of sensors, that will provide a further wealth of information and indicators, whether health, environmental, economic, or social. Where once governments may have had to rely on proxies or estimates, in the near future it is possible that government agencies will be able to draw on unprecedented amounts of real-time data about the world around them. (For a further look at potential for data to empower the public sector, see van Oojen, Ubaldi \& Welby, 2019.)

- Relevant and accessible external knowledge: once upon a time accessing knowledge outside an organisation was slow and potentially difficult or costly. It could be hard to find out who knew what, and the sharing of information was slower and more laborious to coordinate. In today's 
connected world, accessing, aggregating and analysing relevant information from outside your team or organisation is vastly easier and dramatically less costly.

- Customer / citizen insights: data and knowledge tell only so much. 'Anecdata' or insights drawn from the lived experiences of citizens and those using government services are also needed. Social media and other real-time feedback mechanisms combined with more sophisticated tools and ethnographic approaches provide a rich source of such insights. It is easier than ever before to obtain not only understanding of what people are doing, but also insights into why.

- Actors with possible influence or impact: in a connected world, it is easier for individuals, teams, networks and small organisations to have an impact, sometimes global in nature. Where once government agencies might have needed to only think about and engage with a small number of powerful institutional actors, now start-ups, social movements, lobby groups and citizen ventures can pop-up very quickly and with significant effect.

- External events or developments that matter: in an interconnected world, events in one field can more easily have cascading ripples across the board. Where once public sector agencies might have limited their monitoring or planning to a small number of situations or scenarios, now developments from unrelated arenas must be considered as potentially relevant.

- Possible futures: in a world with less data and information, fewer actors or events that might have a direct impact on the work of an organisation, planning needed to deal with a much narrower range of possible futures or scenarios. In an interconnected world, with rapid changes in information and technology, there is a much wider range of possible futures, and that makes planning significantly more complex.

- Opportunities: some of the same conditions that have resulted in this shift from scarcity to abundance have also meant organisations are also in a better position to consider and experiment with a lot more ideas. Design thinking, ICT tools, ready availability of data, computational power and simulation - these and other factors mean that the cost of having and testing an idea (to some extent) is far cheaper than it once might have been. It is now far easier to quickly develop, validate and prototype an idea with relevant people - in a way that once would have either been impossible or have taken far more time and resources

These shifts are represented in Figure 2.1.

Figure 2.1. From scarcity to abundance

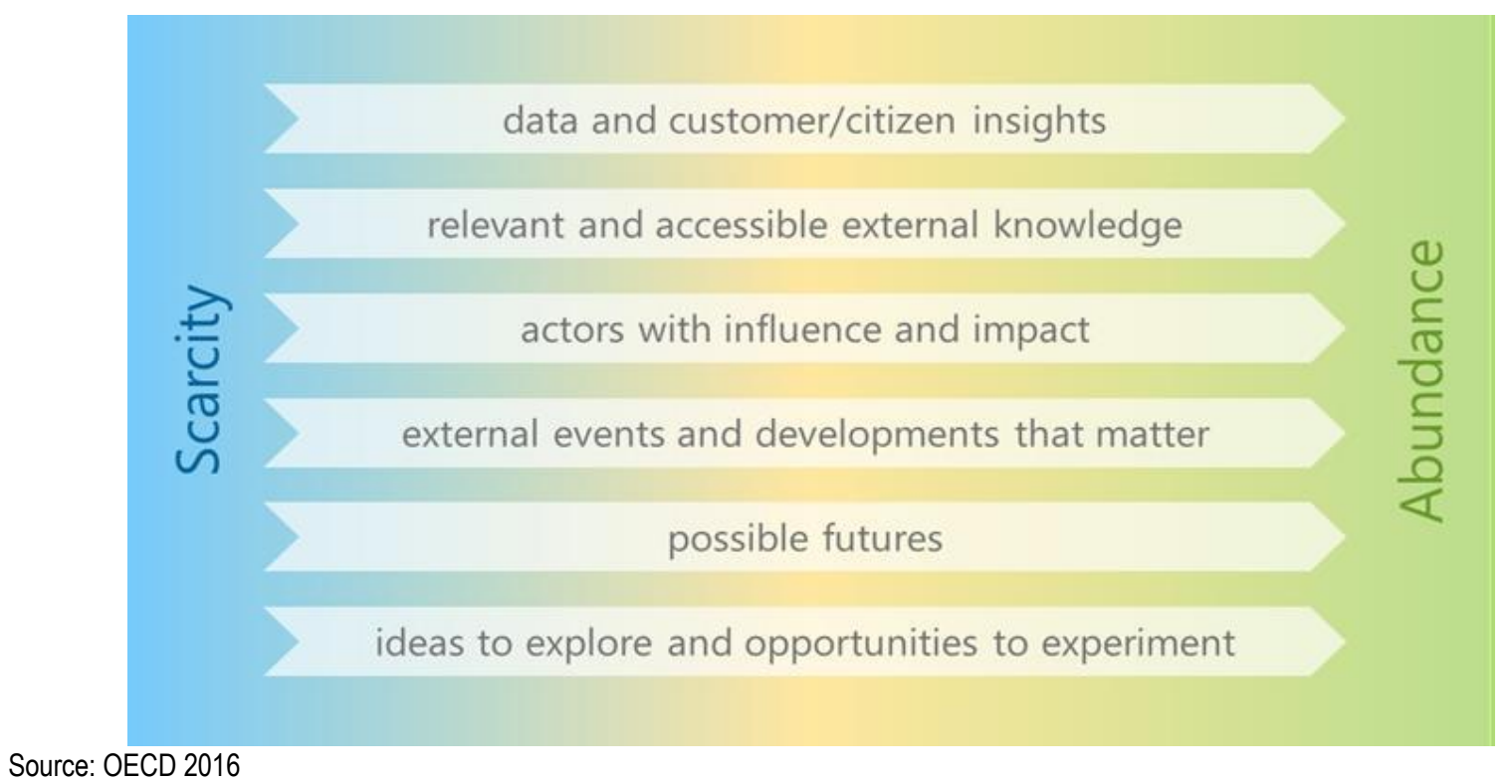




\section{The changed context and the operational level}

What do these shifts mean in practical terms, when it comes to the day-to-day work of those within the public sector? It is possible to further drilldown into the implications of this shift, to see how they may play out at the level of a team or organisation. Table 2.1 outlines how these changes manifest across a range of core operational factors for the public sector (drawing on OECD, 2018a).

\section{Table 2.1. The public sector operates in a new reality}

\begin{tabular}{|c|c|c|}
\hline $\begin{array}{l}\text { Core operational } \\
\text { factors }\end{array}$ & Little change/innovation & Considerable change/innovation \\
\hline Stakeholders/ Actors & $\begin{array}{l}\text { - Relevant actors and stakeholders are likely to be } \\
\text { known or understood } \\
\text { - The capabilities, motivations and intentions of } \\
\text { actors are likely to be relatively understood } \\
\text { The scope of action for existing actors is generally } \\
\text { well-defined or delimited }\end{array}$ & $\begin{array}{l}\text { - New players are likely to emerge, probably with } \\
\text { different skills, attributes and motivations } \\
\text { - The interests of existing actors are likely to change } \\
\text { (potentially towards maintaining position and/or } \\
\text { harnessing opportunity), or the dominant discourse } \\
\text { will likely shift away from the previously understood } \\
\text { and expected positions } \\
\text { - Relationships between and with stakeholders are } \\
\text { more likely to fluctuate and operate with a degree } \\
\text { of flux as the context changes and interests shift }\end{array}$ \\
\hline Knowledge & $\begin{array}{l}\text { - Relevant knowledge (or gaps in that knowledge) is } \\
\text { likely to be known and appreciated }\end{array}$ & $\begin{array}{l}\text { - New knowledge is likely to appear from unexpected } \\
\text { or unfamiliar sources } \\
\text { - } \quad \text { Existing knowledge may be challenged, discredited } \\
\text { or attacked } \\
\text { - } \quad \text { New knowledge may be rejected or devalued } \\
\text { - Verifying new knowledge may be difficult as the } \\
\text { intent and authenticity of new sources of } \\
\text { knowledge may be hard to ascertain }\end{array}$ \\
\hline $\begin{array}{l}\text { Organisational } \\
\text { expertise/ Proficiency }\end{array}$ & $\begin{array}{l}\text { - Organisations are likely to have established and } \\
\text { understood expertise, capability and proficiency in } \\
\text { areas of relevance to their function } \\
\text { - Skills and capability needs for the organisation are } \\
\text { generally well understood, and reflected in } \\
\text { recruitment, management practices and training } \\
\text { and development }\end{array}$ & $\begin{array}{l}\text { - Existing capabilities and expertise may quickly } \\
\text { become insufficient for the issues or challenges at } \\
\text { hand } \\
\text { - New expertise and new capabilities are likely to be } \\
\text { needed and developed, sometimes in tension with } \\
\text { existing expectations, interests, traditions, } \\
\text { processes, cultures and values of the organisation, } \\
\text { making it hard for the skills to be effectively used or } \\
\text { leveraged } \\
\text { Skills needs can be difficult to articulate and } \\
\text { existing training or development practices may } \\
\text { focus more on previous skill areas that are more } \\
\text { easily identified and catered to }\end{array}$ \\
\hline Emergent issues & $\begin{array}{l}\text { - Likely problem areas, while not predictable, are } \\
\text { more often than not unsurprising } \\
\text { Many issues arise slowly over time that (or if a } \\
\text { crisis) can be responded to with a combination of } \\
\text { existing strategies and the application of more } \\
\text { resources }\end{array}$ & $\begin{array}{l}\text { - Weak signals can transform into consequential } \\
\text { trends quickly and unexpectedly, but the difficulty } \\
\text { in ascertaining which will and which will not can } \\
\text { lead to efforts and resources being ineffectively } \\
\text { invested } \\
\text { - Problems come from surprising and previously } \\
\text { unrelated areas } \\
\text { Issues may often be most effectively engaged with } \\
\text { when they are still emergent; however issues at } \\
\text { this stage may not yet be seen as a political issue } \\
\text { or viewed as serious/worthy of scarce } \\
\text { attention/resources }\end{array}$ \\
\hline Planning & $\begin{array}{l}\text { - } \quad \text { Plans and the underlying assumptions are } \\
\text { generally in line with reality } \\
\text { - } \quad \text { Causal relations are generally linear and cascading } \\
\text { - } \quad \text { Resource allocation can be (roughly) predicted and } \\
\text { planned for }\end{array}$ & $\begin{array}{l}\text { - } \quad \text { Assumptions underlying long-term plans often do } \\
\text { not hold true } \\
\text { - Greater flexibility and adjustment is needed as } \\
\text { feedback during implementation points to } \\
\text { unexpected issues }\end{array}$ \\
\hline
\end{tabular}




\begin{tabular}{|c|c|c|}
\hline $\begin{array}{l}\text { Understanding } \\
\text { what works }\end{array}$ & $\begin{array}{l}\text { - There is a shared consensus around what } \\
\text { strategies, tools, approaches and interventions are } \\
\text { likely to be effective under particular sets of } \\
\text { circumstances }\end{array}$ & $\begin{array}{l}\text { - Existing strategies can become less effective as } \\
\text { the environment changes } \\
\text { - Alternate approaches (entirely new or previously } \\
\text { tried or rejected) may promise greater } \\
\text { effectiveness } \\
\text { - Greater experimentation with new approaches may } \\
\text { occur to identify strategies more } \\
\text { effective/appropriate to a new setting }\end{array}$ \\
\hline $\begin{array}{l}\text { Infrastructure/ } \\
\text { Investment }\end{array}$ & $\begin{array}{l}\text { - Understood capability needs, priorities and } \\
\text { preferred interventions can be used to identify and } \\
\text { match infrastructure and investment needs }\end{array}$ & $\begin{array}{l}\text { - Longer-term investments can become difficult as } \\
\text { certainty about the future decreases } \\
\text { - Uncertainty means a focus on standards and } \\
\text { parameters may be more effective than a focus on } \\
\text { specific needs that may soon change } \\
\text { - A portfolio approach that invests in multiple bets } \\
\text { may be more appropriate and/or lots of small } \\
\text { investments in differing options until the most } \\
\text { promising options are identified }\end{array}$ \\
\hline $\begin{array}{l}\text { Decision-making/ } \\
\text { Organisational } \\
\text { priorities }\end{array}$ & $\begin{array}{l}\text { - Decision-making processes and organisational } \\
\text { priorities are understood and relatively stable } \\
\text { Decision-makers share the same information and } \\
\text { are aware of the main issues } \\
\text { - Core operations are unsurprising and associated } \\
\text { responsibilities can be delegated }\end{array}$ & $\begin{array}{l}\text { - Organisational priorities can be subject to quick } \\
\text { changes } \\
\text { - Decision makers may not share, be aware or } \\
\text { familiar with all of the relevant information or issues } \\
\text { - } \quad \text { Novel functions, issues or challenges may require } \\
\text { a significant amount of decision-making attention, } \\
\text { while core functions may need to adjust or change }\end{array}$ \\
\hline Responsibility & $\begin{array}{l}\text { - Responsibilities for particular issues and functions } \\
\text { are clearly demarcated }\end{array}$ & $\begin{array}{l}\text { - } \quad \text { Responsibilities are often blurry, reaching across } \\
\text { formal reporting lines, organisations and sectors }\end{array}$ \\
\hline Leadership & $\begin{array}{l}\text { - Organisations may often have consistent } \\
\text { leadership for long stretches of time } \\
\text { - When leadership change does occur, new leaders } \\
\text { are often selected from within the organisation or } \\
\text { from one with a similar mission/function. }\end{array}$ & $\begin{array}{l}\text { - New or different qualities may be expected from } \\
\text { leaders } \\
\text { - Traditional career paths may not be indicative or } \\
\text { predictive of where future leaders will be sourced } \\
\text { from. }\end{array}$ \\
\hline
\end{tabular}

Source: Adapted from OECD, 2018a

This is not to say these are the only changes that are occurring, nor that all teams or public sector organisations will face all of these changes all of the time. However, the environment for the public sector has irrevocably changed and will continue to change, such that that innovation is (and should be) much more of a concern and a preoccupation than it has been before. A more sophisticated approach to innovation is demanded.

\section{The changed context and the stages of the lifecycle}

In turn, these shifts influence each of the stages of the innovation lifecycle. The changed context demands more from the innovation process than before. Each of the stages of the lifecycle requires further effort than before, if they are to be effective (i.e. helping a team or organisation to develop, deliver and learn from novel responses to problems requiring an innovative response).

For instance, identifying problems is relatively easy in a more stable environment, whereas in this changed context there is an ongoing changing sense of what is possible. Changing possibilities change expectations, which is where there can be gaps between what is and what should be. In a political environment, this creates a problem. For instance, the fax machine never stopped being functional - it was a workable technology. The advent of ubiquitous scanning and email however revealed or made explicit a problem with the fax machine - it was slower and more cumbersome. While the original solution did not change, the occurrence of other, better solutions revealed a problem with the existing solution. As new technologies, business models and ways of working arrive, previously acceptable and functional options become obsolete, redundant or somehow suboptimal. The changed context, and a more rapidly evolving landscape of possibilities and options, means there is increased pressure to question the status quo, to 
see what else is available, and to learn how and where performance needs to improve or change (or even stop). Whereas the ability to learn about problems could have been relatively informal in a more stable environment, an environment in flux requires a more sophisticated learning process to identify issues. This is exacerbated in an environment where expectations can shift quite quickly, and tentative issues can become full-blown problems seemingly overnight.

Equally, idea generation is a more straightforward process when there is a slower or more restrained rate and direction of change, whereas a greater range of possibilities provides scope for a greater range of potential ideas. To illustrate this, consider the example of government communications. Once upon a time, there were a limited number of possible pathways by which a government could communicate to a mass audience - e.g. from newspapers and leaflets, to letters, to radio, to television, to email, to social media. Each provides a greater range of possible options, and each sparks a whole new dimension of the manner of communicating. Now there is a context of an interconnected world where there are more actors than ever before (people, firms, community groups, etc.), actors that are more empowered with, and by, technology than ever before, and many are more educated than ever before. At the same time all of these actors have access to all of humankind's collective knowledge. In this context, idea generation moves more from 'we need ideas' (because there is no shortage of ideas) to 'we need to 'find and filter the best ideas' (because picking which idea becomes harder when there are so many possible choices). Think tanks, private businesses, NGOs, individuals, prize challenges and competitions, academia, ideas platforms, citizen juries - the list of potential sources of relevant ideas is ever-growing. In a crowded marketplace of ideas, the public sector will often not be the source, or even implementer, of ideas, but will have to collaborate with others on their ideas, or even empower others to act on their own ideas. These factors heighten the political nature of idea generation - whose ideas are given preference and/or selected - so that the means by which ideas are filtered become particularly important.

Likewise, the development of proposals as to what to do (or not do), what to invest in, or what to attempt is far easier in an environment of stability than in an environment in flux. Greater uncertainty means that it is difficult to not only know which project or initiative might have the most merits, but also whether an idea will unfold as intended once it is implemented. For instance, choosing which renewable energy technology to roll-out in order to reduce climate emissions becomes more complicated when there are a range of possible technologies, all of which are changing and developing - if the relative cost profiles and performance do not stay constant, then it is harder to create a stable long-term strategy. In such a context, maturing ideas and testing them before deciding upon which to commit to becomes more important, as it is desirable to better understand the relative merits of the ideas and ensure they can be better understood and communicated to decision-makers. This, in turn, necessitates new ways of engaging with people to ensure the intent would be matched by the implementation - i.e. do the assumptions contained within the project proposal actually accord with what would happen given a changing context where new behavioural patterns may emerge.

Project implementation is also complicated in a high-change environment. No matter how good or thorough the proposal, the delivery of a project in a changeable and changing situation is going to involve some surprises. Ensuring the project can adjust as more is learnt, while at the same time staying true to the project intent, can be a difficult balance. For example, governments have been building roads for thousands of years - this is 'bread and butter' for the public sector. Yet, in a changing climate the expectations of what the road may need to deal with may be challenged, traffic assumptions may be shaken by ride-sharing and autonomous vehicles, changing real-estate preferences and costs may shift traffic patterns, and new scientific knowledge about the health effects of traffic noise may all contribute to challenge the design and implementation of road building and financing. Project implementation is complicated further if, and when, there are other projects or initiatives being introduced or carried out at the same time, thereby further complicating and changing the context in unknown ways. Whereas once project management might have been about clear milestones, known risks, expected resources and skills requirements, innovation often 
benefits from a more iterative process that allows changes as more is learnt so the project can adjust to the new understanding of what is possible and needed.

The complications continue when it comes to the evaluation of projects. A more stable environment offers an easier context for assessing project outcomes, as it is easier to see whether and how a novel intervention has made an impact. On the other hand, an environment with high change offers a challenging situation for tracking and understanding what has happened, as a shifting context can make it harder to isolate the specific impacts of any one intervention or contribution, even with controls or parallel experiments. An illustration of this complexity is provided by the example of reducing urban crime. A strategy might be introduced of having more police patrol and to increase the penalties for minor incidences (the 'broken windows' strategy). This could see significant results, giving the impression the strategy was a success. Yet, taking a broader view, there might be other possibilities (e.g. the 'lead-crime hypothesis which argues that as exposure to lead from paint and petrol has reduced, there has been a drop in violent crime) and new factors that will complicate things (e.g. research suggesting that the warmer temperatures that come with climate change will see more violent crime). The uncertainty affecting the implementation phase may also mean that the nature of what is being done varies during the life of the project from what was originally intended, further confusing what it is that is actually being measured, assessed or evaluated.

The challenges are no less significant when it comes to diffusing lessons. In a stable environment, it is easier for any one organisation or team to identify other areas that are in comparable situations or experiences (e.g. counterpart teams in like-organisations), and to whom they should look for relevant lessons. It is also easier to identify those who might benefit from the insights gained from some activity, and thus who it might be beneficial to share experiences with. An environment experiencing a high degree of change also makes it difficult to identify the particulars of a project and what the relevant parameters or preconditions might be for successfully adopting or adapting the initiative to another context. This extends to time, as well as place, as the temporal nature of the context becomes as relevant as the place of implementation. Lessons from one year may be different to lessons from another, due to political, social, environmental and economic differences.

Table 2.2 provides an overview of the contrast between low change and high change environments and the implications for the different stages of the innovation lifecycle.

\section{Table 2.2. How a changed context affects each stage of the innovation lifecycle}

The contrast between low change and high change environments

\begin{tabular}{|c|c|c|}
\hline & Little change/innovation & Considerable change/innovation \\
\hline Identifying problems & $\begin{array}{l}\text { Relatively stable possibilities mean problems often fit } \\
\text { within a set spectrum of possibilities. Problems are } \\
\text { thereby often relatively well understood, or fit within } \\
\text { expected areas of expertise and competence. }\end{array}$ & $\begin{array}{l}\text { Changed possibilities mean the status quo can be looked } \\
\text { at in new ways. New and rapidly changing possibilities, } \\
\text { and the associated changing expectations, ensure it is } \\
\text { no longer safe to assume the current state is the optimal } \\
\text { one, and thus there needs to be continual reflection and } \\
\text { learning about new problems that may have arisen or } \\
\text { how old ones may be changing. }\end{array}$ \\
\hline Generating ideas & $\begin{array}{l}\text { If change is slow or minimal, then the range of } \\
\text { possibilities that can, or need to, be considered are likely } \\
\text { to be limited. In a known environment, the chance of } \\
\text { being surprised by ideas or possibilities is relatively low. }\end{array}$ & $\begin{array}{l}\text { A greater range of possibilities results in more possible } \\
\text { ideas and opportunities. Simultaneously there is less } \\
\text { certainty as to which ideas will work or how they will work } \\
\text { in practice, as the context they are intended for is } \\
\text { changing. Greater interconnections means there are } \\
\text { more actors who will have relevant ideas, as well as } \\
\text { greater feedback about any ideas, and a greater chance } \\
\text { that any idea will have spillovers into other sectors, } \\
\text { domains or audiences. }\end{array}$ \\
\hline Developing proposals & $\begin{array}{l}\text { If change is slow or small, the merits of an idea are easier } \\
\text { to assess, and there's more time to test and evaluate } \\
\text { options before needing to act. The decision-making }\end{array}$ & $\begin{array}{l}\text { An environment of change means it is harder to assess } \\
\text { proposals because as the context shifts, so too will the } \\
\text { merits of an idea, as well as how it fits with the existing }\end{array}$ \\
\hline
\end{tabular}




\begin{tabular}{|c|c|c|}
\hline & $\begin{array}{l}\text { ecosystem is also likely to be relatively stable, meaning } \\
\text { there is a high degree of familiarity with how decision- } \\
\text { makers think and their preferences for ideas and how } \\
\text { they are presented. }\end{array}$ & $\begin{array}{l}\text { constellation of initiatives and priorities. Innovation also } \\
\text { involves a degree of trust/faith, which can be harder to } \\
\text { gain or sustain if the relevant actors (particularly } \\
\text { decision-makers) are often changing. }\end{array}$ \\
\hline Implementing projects & $\begin{array}{l}\text { Slow or small change means project plans can better } \\
\text { map to the actual reality of project delivery. If the plans } \\
\text { stay relevant, then it is easier to map the necessary skills, } \\
\text { capabilities and resources that might be needed and } \\
\text { likely points of needed scrutiny or reassessment. }\end{array}$ & $\begin{array}{l}\text { High uncertainty suggests a need for a more agile or } \\
\text { dynamic approach to project management that can } \\
\text { respond to unexpected circumstances and unexpected } \\
\text { lessons/insights, as there can be increased confidence } \\
\text { that there are going to be gaps between what is predicted } \\
\text { in a plan and the reality that will unfold. }\end{array}$ \\
\hline Evaluating projects & $\begin{array}{l}\text { A context of low change means it is easier to have a } \\
\text { clearer sense of the relationships between different } \\
\text { interventions, and thus whether a specific intervention } \\
\text { had the desired effect. }\end{array}$ & $\begin{array}{l}\text { High uncertainty means there may need to be a range of } \\
\text { experiments and controls to test for the optimal strategy } \\
\text { or response. Even when this occurs, it may be difficult to } \\
\text { isolate the causal links or argue the counterfactual, given } \\
\text { a highly dynamic system with continually shifting } \\
\text { parameters, as well as potential shifts in what is being } \\
\text { aimed for or desired from the innovative activity. }\end{array}$ \\
\hline Diffusing lessons & $\begin{array}{l}\text { A slower moving context means it is easier for those } \\
\text { seeking new information to identify parallel experiences } \\
\text { that may be relevant to the situation at hand. It is also } \\
\text { easier for those willing to share their experiences to know } \\
\text { which partners and counterparts might benefit from the } \\
\text { insights gained. The relevant specifics of the lessons, or } \\
\text { the necessary preconditions, are also likely to be easier } \\
\text { to map. }\end{array}$ & $\begin{array}{l}\text { Greater fragmentation means it is harder to know what } \\
\text { the underpinning lessons were, what the relevant } \\
\text { contributing factors were, or what the success conditions } \\
\text { are, or to what extent projects might scale across } \\
\text { differing environments. A sense of time as well as place } \\
\text { becomes a variable, as the temporal context matters as } \\
\text { much as the particulars of where the innovative initiative } \\
\text { was tried. }\end{array}$ \\
\hline
\end{tabular}

Source: New material and drawn from OECD, 2016, 2017b, 2018b, 2018c, 2018e, $2018 f$.

\section{Innovation is a process but an uncertain one}

For each stage of the lifecycle there are innumerable possible considerations and issues. This chapter does not seek to outline them all. Rather, given each of these stages are things that public sector teams and agencies have been doing previously (and often quite successfully), the key issue is to recognise what is making it different from before. By understanding what is changing the operating environment, the team or organisation may be better able to self-asses their efforts and to reflect on what might need to change. There can be no precise roadmap for the process, given innovation is inherently about context (because what is novel to the context depends on what that context is). If every journey will be different, it is more important to understand how the contours have changed, rather than step-by-step instructions that will soon become out-of-date or ill-suited to the particulars at hand.

In short, despite providing insight into the changed context, and a sense of its implications for each stage of the innovation lifecycle, the innovation process for teams and organisations will continue to entail a great deal of uncertainty. Such uncertainty can make it difficult to make the case for a deliberate approach to innovation, even when there is acceptance that sticking with the current path may not be the best option (or the best option for very long). Why resource something that may not even deliver what is intended or asked for? Even knowing that things will need to change, it can be easier to concentrate on the tasks at hand, especially if the alternative is messy and ambiguous.

What can be done to help combat this uncertainty and to make the case for a deliberate, explicit and organised approach to innovation in a team or organisation then? The next chapter explores how to maximise the benefits of an uncertain process by taking a portfolio approach. 


\section{A multifaceted portfolio approach}

Even at the best of times, and even when supported with a rigorous process, innovation is an uncertain activity. Individual projects can have a high rate of failure, which can create difficulties for teams and organisations in creating the business case for innovation. A portfolio approach can help to ensure that innovative projects can be seen as investments rather than bets, and a multifaceted view of innovation can help provide different perspectives on what is trying to be achieved. 


\section{The innovation process is stronger when complemented by a portfolio approach}

Even without the high uncertainty of today's world, described in Chapter 2, an innovation process offers no guarantees. Doing something new to the context brings its own uncertainty, on top of the potential issues that can strike a more established or well-known project or initiative. Even if the innovation process runs smoothly, and if each stage of the innovation lifecycle is carefully considered and supported, the innovative activity may fail - either to deliver as intended or even to produce lessons and insights relevant to the situation at hand. Therefore, teams and organisations need to consider not only the lifecycle stages of the innovation process, but also view innovation from a portfolio perspective. The risk of any single incremental innovation project failing to deliver as hoped for is relatively high, let alone for those that verge on new-to-world or that are more radical in nature. When viewed as part of a portfolio however, the costs of a failed innovation are more easily seen as an investment, as the lessons can be leveraged for other projects and efforts, rather than as sunk costs.

A portfolio can be considered in regards to running multiple experiments at once on a specific problem. This will provide a higher chance of success and pay-off, but it can be considerably more resource and time intensive, and so may not be appropriate or possible (e.g. running multiple projects to test for solutions against a single policy issue is rarely politically feasible or appropriate). A portfolio approach is likely to be more feasible across a range of projects and initiatives cutting across multiple problem spaces, with projects assessed through the wider lens of innovation as a practice.

What might such a portfolio look like or how might such a portfolio be categorised?

One framework that can guide a portfolio perspective is the OECD's facets framework (2018g), which outlines how public sector innovation is not just one thing, but varies according to purpose and whether it is exploitative/incremental and exploratory/radical; or whether it is more top-down and directed or rather more bottom-up, responding to changing circumstances and thus more undirected in nature.

\section{Figure 3.1. Innovation is multifaceted}

\section{OPSI}

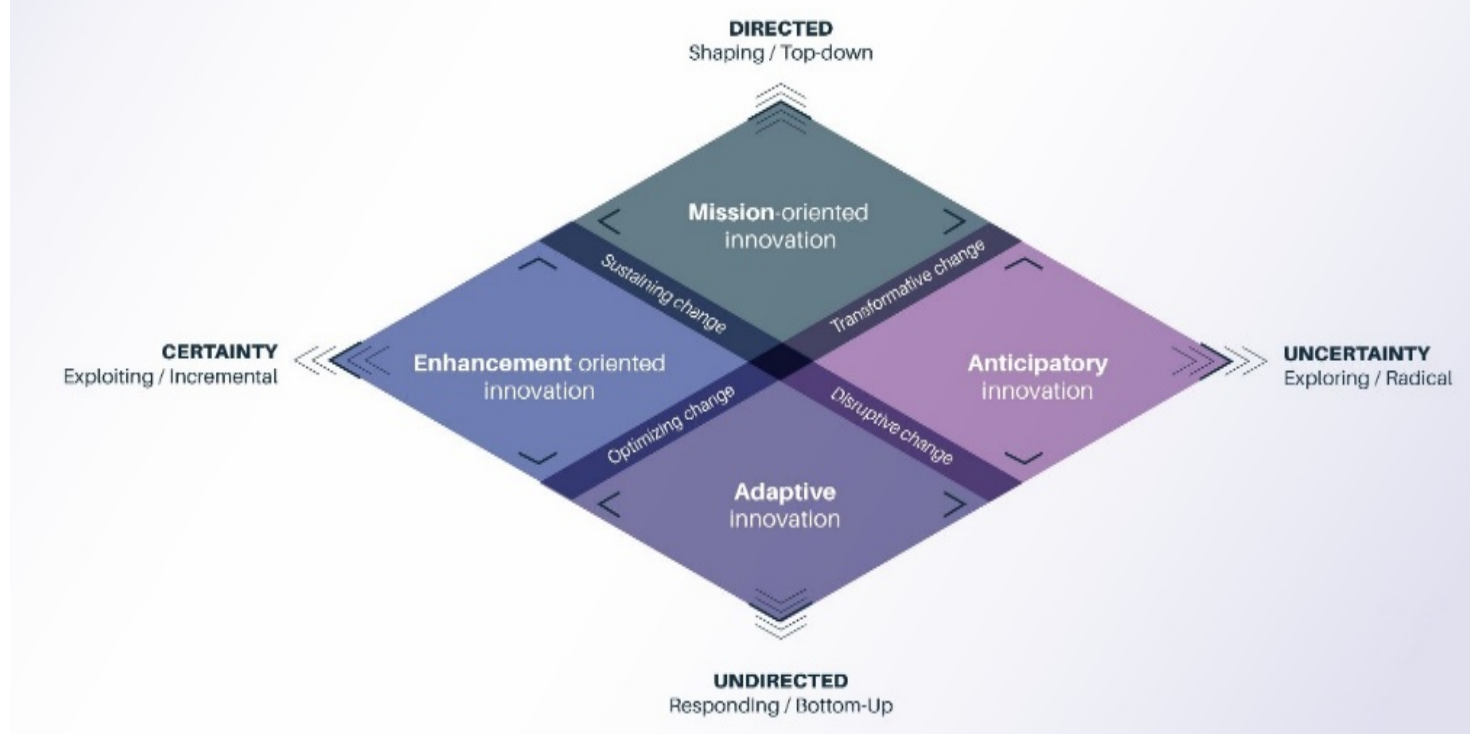

Source: $\mathrm{OECD}, 2018 \mathrm{~g}$ 
Activity in each of the facets have differing aims and different spurs:

- Enhancement-oriented innovation: this often starts with the question of "How might we do $X$ better?" It is not about questioning what is being done, but rather how it is done and whether it can be done differently, and hopefully better.

- Mission-oriented innovation - this is about asking "How might we achieve X?", with X ranging from the world-changing (going to the moon) to the significant but relatively contained (ensuring better services). It starts with a driving ambition to achieve an articulated goal, though the specifics of how it might be done are still unclear or are not set in stone.

- Adaptive innovation: this starts with the question "How might our evolved situation change how we do X?" Adaptive innovation is essentially about a realisation that things are happening that do not fit with what is expected.

- Anticipatory innovation: this starts with the question of "How might emerging possibilities fundamentally change what X could or should be?" with X being the relevant government response or activity. Anticipatory innovation is essentially about recognising and engaging with significant uncertainty about not only what works, but also what is appropriate or possible.

Activity in each facet has differing strengths and contributions, as well as weaknesses and drawbacks. Therefore a mix of activities will be desirable. The exact mix however will depend upon the context, what is feasible for an organisation or team, and what is happening in the surrounding ecosystem.

Accordingly, the facets model provides a frame by which teams and organisations can consider their existing activity, and reflect on what mix of activity might be needed or appropriate given their context, priorities and ambitions.

\section{Using the facets as prompts for the lifecycle stages}

The facets model can also be used as a prompt for each of the lifecycle stages. By considering the differing types of innovation activity, the facets model allows for deeper reflection on each element of the innovation process. Identifying problems can look very different when viewed through the different facets. For instance, a problem or issue will present itself in very different ways if it was considered through a more incremental, enhancement-oriented innovation perspective than an anticipatory one. e.g. if the future of work is taken as an issue, an anticipatory angle might be about how the nature and value of work may need to evolve as automation becomes more sophisticated, whereas an enhancement-oriented point-ofview might be about improving employment programmes/engagement with employers about skills needs. Equally, evaluation will look very different for an adaptive vs a mission-oriented project (removing pain points vs large-scale shift in outcomes).

How might the facets be used as prompts for each of the lifecycle stages? The following illustrates some of the questions the facets can prompt for the differing stages of the innovation process.

\section{Identifying problems}

- Enhancement-oriented: What parts of core business are not delivering as effectively as they could? Where is existing performance falling short of what is possible or what might be expected?

- Mission-oriented: What are the big issues that need addressing? Where are the gaps where a big audacious goal might make the difference?

- Adaptive: What changes in the operating environment are not being responded to effectively? Where are the gaps between what was intended and what is actually occurring?

- Anticipatory: What are the signs things might not continue as they have? Where are the issues that could surprise? 


\section{Generating ideas}

- Enhancement-oriented: What is already being done by the team or organisation that could be built upon? What are the existing successes that could be leveraged further?

- Mission-oriented: What is it the team or organisation is really seeking to achieve and how does that align with broader agendas? What are the goals or aims that could mobilise and leverage the efforts of others in the broader ecosystem?

- Adaptive: What are others doing or trying that is working that could be adopted or adapted? What could now be possible that was not before?

- Anticipatory: What are some divergent possible futures and what do they suggest could need to change? What would happen if existing assumptions about the future were challenged?

\section{Developing proposals}

- Enhancement-oriented: How is this proposal beneficial to what is already being done by the team or organisation? In comparison with other options, what does this proposal offer to the core business of the team or organisation?

- Mission-oriented: How does this proposal help to drive the change needed or wanted by the team or organisation? In comparison with other options, what does this proposal do to enable others to contribute to the priorities of the team, organisation or more broadly?

- Adaptive: How does this proposal help the team or organisation better respond to the on-theground realities? In comparison with other options, what does this proposal do to respond and learn from a shifting context?

- Anticipatory: How does this proposal reduce the uncertainty of what might happen next? In comparison with other options, what does this proposal do to help inform the future work of the team or organisation?

\section{Implementing projects}

- Enhancement-oriented: From an enhancement perspective, what does failure look like or what is the threshold for project re-appraisal?

- Mission-oriented: From a mission perspective, what does failure look like or what is the threshold for project re-appraisal?

- Adaptive: From an adaptive perspective, what does failure look like or what is the threshold for project re-appraisal?

- Anticipatory: From an anticipatory perspective, what does failure look like or what is the threshold for project re-appraisal?

\section{Evaluating projects}

- Enhancement-oriented: How has the existing situation been enhanced or improved upon? What new possibilities are there that might mean that what is now being done may no longer be appropriate?

- Mission-oriented: How has the mission progressed? In what ways has the context changed that might mean the mission might need to change or alter course?

- Adaptive: How has the gap between the intent and on-the-ground reality been reduced or overcome? Is what is being done a symptomatic response to a broader underlying issue or need?

- Anticipatory: What has been learnt or unlearnt about how the future may unfold, and how does this challenge existing assumptions? How will this inform practice now or in the near future? 


\section{Diffusing lessons}

- Enhancement-oriented: How can these lessons be leveraged for other existing activity by the team or organisation? In what ways can the specific initiative be further extended or scaled-up?

- Mission-oriented: How do these lessons help further the mission? How can the lessons inform other missions?

- Adaptive: How do the lessons challenge existing practices in policy and programme delivery? What are the implications for other parts of the organisation or ecosystem in how they engage with the changing context?

- Anticipatory: How do the lessons learnt (or unlearnt) about the future undermine or necessitate a shift in the presumptions of the work of the organisation or the broader ecosystem? How can the futures explored be used to build a richer understanding of the changing context for other parts of the organisation or ecosystem?

\section{Innovation takes place within a broader ecosystem}

Innovation can be a daunting activity. A team may be good at certain stages of the innovation lifecycle or have strengths in particular types of innovative activity across the facets, but it is unlikely to be excellent at all elements or all facets. Even a large organisation will likely have weaknesses within the lifecycle or across the facets.

Every team or organisation can identify its innovation strengths and cultivate and maintain an innovation portfolio of some extent, ensuring not just a mix of projects but that the lessons from each inform the others. This portfolio will inevitably have gaps, however, reflecting resource, reach, time, talent or other limitations. In order to mitigate the limits of its own portfolio, and the potential inability to cover projects and experiments across every facet, it can be helpful, therefore, for a team or organisation to consider their surrounding ecosystem. 


\section{An ecosystem perspective}

Public sector innovation is a collective endeavour. Even when a particular innovative project relates to the inner workings of a team or an organisation, its public sector nature means that its broader context matters. What happens in one area will affect or relate to others, as no policy is an island, no service an orphan. Public sector innovation should therefore have regard to the broader ecosystem, including flow-on effects, dependencies and interconnections, as well as looking at how public value can be enhanced by including (or leveraging) other actors, their capabilities and their potential contributions. 
An ecosystem perspective is valuable for any team or organisation seeking to take a process-oriented view of innovation. The success of any change effort, let alone one where there is significant uncertainty, will be dependent upon more than just the immediate team or organisation.

To illustrate this, consider that in an interconnected world, innovation is not just about changing the immediate context. If the public sector changes one part of its context through a novel initiative, it is also changing the context for others as well, whether they be stakeholders, partners or citizens more generally. An internal process change, if innovative, will still have flow-on effects that will matter to others.

Innovation is also about changing something - process, policy or programme - and this ultimately comes down to changing behaviours e.g. getting better health or education outcomes is not a passive process it necessitates behaviour change in some way, whether by patients or students, or by doctors and teachers. This behavioural change cannot be simply directed or mandated to be effective - it requires some degree of volition from the people involved.

In this way, public sector innovation is inherently a social activity. Innovation must be appreciated and understood as occurring across and within an ecosystem. The extent to which an innovation succeeds will depend upon others in the ecosystem - their capabilities, their interests, their needs, their attitudes and the receptivity to new ideas and approaches. In addition, innovative activities can also generate resistance or pushback, and thus it can be important to understand those perspectives and appreciate what might underlie a negative reaction.

There can also be considerable benefits for teams and organisations that take an ecosystem perspective. For instance, the social and interconnected nature of public sector innovation is also vital in a context of interlinked problems and policy issues. Using the example of the health sector to illustrate, success in health depends in part on success in education, transport, agriculture and urban planning, and thus the other players in the ecosystem will matter, either as a source of intelligence about what problems there might be or as a potential implementation partner.

Additionally, innovation can be a costly exercise. Attempting new things, building new capabilities, testing new approaches and searching for solutions to problems can be resource intensive. Learning from and sharing and partnering with others can reduce the cost of experimentation and mitigate some of the risks of any one project failing. Common challenges can be a catalyst for common causes, and having regard to the broader ecosystem can help teams and organisations build a more rigorous and effective portfolio, at the same time as mitigating some of the costs involved.

Public sector teams and organisations can therefore benefit on a number of fronts if they actively appreciate and cultivate their innovation ecosystem.

\section{Segmenting ecosystems}

What constitutes an ecosystem? The term is somewhat broad. What is actually meant by the word, other than the fellow organisations and actors that are in the same context as the team or organisation considering their ecosystem?

For the purposes of public sector innovation, it is possible to consider five broad groupings under the umbrella term of 'ecosystem' (OECD, 2017b: 71-73).

- The 'community', meaning broader society, whether individual citizens, social movements or community groups

- The political class, meaning politicians and those closely engaged with the political process

- Internal contributors and partners, meaning those working within government and the broader public sector (e.g. state-owned enterprises, schools, teachers, police, etc.) 
- The 'supply chain' for government, meaning those involved in the delivery of government mandated services (such as suppliers and service delivery groups) or conducting research paid for by the government (such as universities and research bodies)

- 'Outsiders', those at the edge that might not necessarily be reflected in the other segments.

None of these groups are mutually exclusive, and a single person, team or organisation may well fit in several of these categories. For instance, a media organisation may be seen as part of the broad community in its role of sharing information and serving as a forum for discussion, as part of the political class because of its editorial line taking political positions, and also as part of the supply chain where it works with government (e.g. on promoting a healthy living campaign or delivering information about vaccines). Nonetheless, these categories can aid in thinking about the differing possible roles, motivations, contributions and capacities for actors and how public sector organisations and teams may relate to them.

\section{Community}

Depending on the context, this might mean or refer to citizens, taxpayers, businesses, not-for-profit organisations, affected or relevant geographic communities or the citizenry as a whole. The community may be very specific (i.e. people in a particular location relating to a specific issue) or it may be broad (i.e. a general sense of the community across the nation, with the broadest notions of identity, aspirations and needs). The political process may often seek to have (or to claim) the support of the 'community' for particular innovations.

\section{Political}

Political actors include politicians and advisors, lobby groups, think tanks, activists and vested interests. These actors may be aligned with the dominant government narrative/perspective, or be in conflict, or both. Significant innovations are often in tension with the dominant paradigms and rhetoric meaning there will be strong political interest. Even for small innovation that may result in less disruption or fundamental shifts, there can be political interest. In other situations, a government can adopt a particular ideology or line-ofthought that embraces and advocates for particular types of innovation (e.g. deregulation, digital transformation or devolution).

\section{Internal}

Internal groups may refer to those within the same organisation, or this grouping might include other parts of the public sector within the same jurisdiction or level of government. Internal groups may be immediate colleagues, other public sector employees in general, other government agencies, functional areas such as HR, finance, or audit, or refer to communities of practice or informal cross-government networks.

\section{Supply chain}

There are generally many organisations and groups involved in the development and delivery of government policies and services, including many non-state actors such as businesses, not-for-profits, academia and think tanks. Governments generally also fund a considerable amount of research (including industrial research and development (R\&D) activity), whether it be through dedicated research agencies, through pre-procurement funding, or through universities and other research organisations.

\section{Outsiders}

Who or what constitutes an 'outsider' may vary between contexts, but will generally mean those who through circumstance and/or necessity use or interact with government in ways that are significantly different to the standard. This might be early adopters, lead users, those at the margin, or those with counter-cultural perspectives. It might include disruptors, those with a different vision for how government 
should or could work, or simply be those from other contexts (e.g. other countries) but with relevant experience or expertise that could potentially be leveraged. Such outsiders are unlikely to have regular contact or established relationships with the team or organisation (or even perhaps be aware of them), and thus it may be difficult to engage them, or to translate their perspective to the context at hand.

\section{Figure 4.1. Understanding the different segments of the ecosystem}

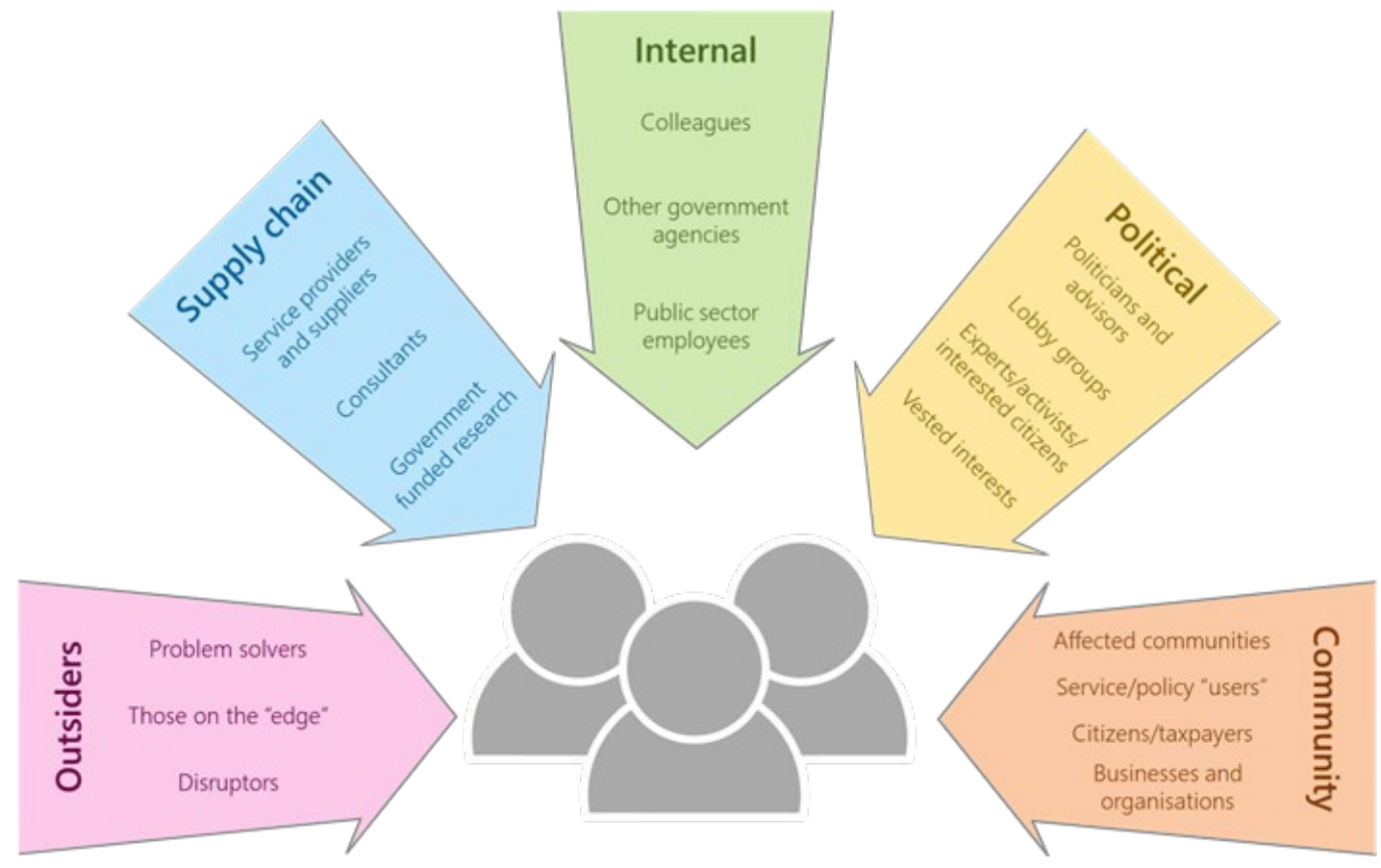

Source: OECD, 2017b: 72

These groups are likely to already be participating, contributing or otherwise shaping the policy and programme work of the public sector in some way, however their involvement may shift when it comes to more innovative work which promises to change how things are done. The channels or means by which they engage with government may differ when it comes to informing, participating, or even resisting or challenging innovative activity.

Any organisation or team seeking to engage with the different segments will need to consider whether there is an established or pre-existing relationship with the respective segments. For actors who are more removed or disconnected with the specifics of a policy domain or the proposed innovation, being asked to participate or engage in some way may not be appealing or resonate with their interests. Involvement from those outside of the normal channels, and thus those who are most likely to have surprising or novel perspectives, should not be assumed or expected, particularly if there have been no efforts to cultivate the relationship.

While each segment should be appreciated and respected in different ways according to their role and perspective (e.g. an average citizen will rarely have the same level of expertise or specific knowledge as a long-term public servant but will, however, know and appreciate the realities of their lived experience better), and are likely to vary in how or on what they prefer to engage (e.g. a large business may identify policy issues that they feel are limiting their business growth, while a research body may provide detailed briefing to the public service and the relevant ministers or senior executives), they can each contribute to each stage of the innovation lifecycle, if cultivated appropriately. 


\section{The lifecycle as a prompt for considering ecosystem relationships}

The lifecycle can provide a prompt for the different ways of valuing and appreciating the contributions of different ecosystem actors. Table 4.1 outlines some of the ways this can be done.

Table 4.1. What might be sought from the ecosystem at different stages of the lifecycle

\begin{tabular}{|c|c|}
\hline Lifecycle stage & Potential role of ecosystem players and actors in the innovation process \\
\hline Identifying problems & $\begin{array}{l}\text { - Source of intelligence about potential problems, gaps between current and expected } \\
\text { performance } \\
\text { - Provider of alternate perspectives for problem solving } \\
\text { - Source of complaints, indicating pain points or alternate ways of doing things }\end{array}$ \\
\hline Generating ideas & $\begin{array}{l}\text { - Contributor of ideas/perspectives about what is needed } \\
\text { - Source of existing solutions that can be used, adopted, adapted or scaled-up } \\
\text { - Complainants, identifying specific things that they wish to see }\end{array}$ \\
\hline Developing proposals & $\begin{array}{l}\text { - Participants in testing and iteration processes } \\
\text { - Providing feedback on prototypes, proposals, models or early-stage trials } \\
\text { - As experienced actors that can identify potential implementation issues, or possible flaws } \\
\text { or strengths of the proposal, or potential unintended consequences } \\
\text { - Source of alternate ways to communicate the proposal, to suit different/varied audiences }\end{array}$ \\
\hline Implementing projects & $\begin{array}{l}\text { Delivery partners } \\
\text { - Providing feedback on implementation issues } \\
\text { - Identifying what is working, what is not, and any variation from expected or desired outputs } \\
\text { and outcomes } \\
\text { - Source of ideas for refining or improving the implementation }\end{array}$ \\
\hline Evaluating projects & $\begin{array}{l}\text { Source of data about the initiative } \\
\text { - External evaluators of the initiative } \\
\text { - Source of qualitative data about the realities of the outcomes, what happened and why } \\
\text { - Identifying unexpected and unintended consequences } \\
\text { - Helping to assess the opportunities for next steps }\end{array}$ \\
\hline Diffusing lessons & $\begin{array}{l}\text { - Identifying how the impact of the initiative might be extended or built-upon } \\
\text { Input on how/if it works in other contexts, which can provide important intelligence for the } \\
\text { original area } \\
\text { Potential partners. }\end{array}$ \\
\hline
\end{tabular}

\section{Public sector innovation driven from outside the public sector}

Public sector innovation can relate to a novel outcome (e.g. a new service), the process for getting to that outcome (e.g. using co-design), and the support provided to facilitate that process (e.g. an innovation lab is used to support the team undertaking the co-design process to get the innovative outcome) (Nählinder and Eriksson 2019, in Lewis, 2019). Public sector innovation will often be driven by public sector agents (e.g. public servants, public institutions, government-owned enterprises, etc.), and, as noted, it will often involve or affect actors from across the ecosystem.

However, sometimes public sector innovation may be driven by actors that are more outside than inside the public sector. This might be a non-government organisation that develops a new service model that is 
later adopted by government for other services. Or it might be a private firm that develops a new medical technology that dramatically reduces operating times and costs for a medical procedure. By its very nature of being about society, public sector innovation can come from anywhere (though whether it is sustained or integrated is often up to, or determined by, the public sector itself).

This paper has been written to assist public sector teams and organisations in considering their innovation process, and therefore does not look at the specifics of how public sector innovation can be driven by outside groups (something that will, by definition, be outside of their control). Nonetheless, an ecosystem perspective, particularly in combination with a portfolio approach, will likely help teams and organisations to better engage with externally driven innovation when and if it occurs.

\section{The lifecycle in practice}

The next chapter examines different examples of the lifecycle in practice, to illustrate some of the considerations involved for teams and organisations seeking to introduce novel initiatives with impact. 


\section{The innovation lifecycle in practice}

This chapter explores some of the characteristics of each stage of the lifecycle. It takes a number of innovative cases to provide insight into some of the key issues and factors that influence the success of each stage. 
What do the different stages of the innovation lifecycle look like in practice?

Any innovation will likely reflect all of the stages of the innovation lifecycle to some degree, and so there are any number of examples that can be shown - for instance the OECD Observatory of Public Sector Innovation has a case library containing several hundred diverse examples from around the world. These highlight the varied nature of innovation, including how sometimes similar-seeming examples can play out very differently in practice.

However, the following selects a number of cases to provide a richer illustration of the different lifecycle stages. This illustration is necessarily partial, as the factors of relevance to each stage are numerous. Nonetheless, they are intended to provide teams and organisations with a greater appreciation of what is involved in each stage.

\section{Identifying problems}

Identifying problems - learning to identify and understand the need for innovative responses - can be done in myriad ways. It may include starting afresh with a policy issue and asking "what is it that we are trying to achieve" or it might be about learning about problems as part of routine business, to identify when and where novel approaches might be needed to keep things running smoothly.

One case (Box 5.1 highlights some of the ways that identifying problems can be an explicit process of asking as well as a background process of understanding changes in the environment.

\section{Box 5.1. San Francisco Fix-lt Team}

In May 2016, the Mayor of San Francisco launched the Safe and Clean Neighborhoods Promise. This was a new initiative to improve the quality of life in San Francisco with a coordinated approach to delivering City services better and faster. The Mayor issued an Executive Directive to Department Heads responsible for quality of life issues directing them to prioritize services so all residents have access to clean, safe, maintained public spaces and facilities. To ensure success, the mayor created the Fix-It Team.

When Fix-It was formed in 2016, it immediately began work in five areas within San Francisco neighbourhoods ("Fix-It Zones"), where a significant amount of residents had been voicing quality of life concerns to the Mayor. In an effort to utilize data as the Fix-It Team expanded its scope of work in 2017, the Fix-It Team worked with the Mayor's Office of Civic Innovation to create an equitable, transparent and data-driven model to determine the Fix-It Zones. This process included collecting resident feedback through community surveys and an analysis of mapped 311 data and police data.

The Fix-It process is summarized over 5 stages: Identification of the challenges and opportunities (data and information gathering), Evaluation (mapping concerns and walking the area with the residents), Validation (walking the area with the responsible City agencies), Execution (action plan creation and service monitoring), and Reporting (sharing successes and roadblocks with residents, survey and feedback).

When working in Fix-It neighbourhoods, residents are encouraged to voice any and all issues pertaining to their neighbourhood's public spaces. However, the Fix-It Team works to set expectations with residents by defining quality of life issues as issues primarily focused on the built environment, issues that do not require a capital investment to address and resolve, such as sidewalk cleanliness, street lighting, bus stop and street conditions, graffiti, and more. In addition to these types of issues, Fix-It works with City agencies in order to provide residents with timely and accurate information about 
processes to address health and human service concerns, such as encampments and discarded syringes, as well as infrastructure concerns, such as streetscape improvements and traffic calming.

Most of the Fix-It Team's time is devoted to problem-solving by analysing data, listening to residents, and working with City agencies to create a set of specific, measurable, and realistic actions to take in each zone. After creating an action plan, Fix-It is responsible for executing quality service delivery and ensuring follow through from agency partners. Throughout the entire process, residents receive consistent communication, with responses to their questions and reports back with results. Fix-lt is also active on social media, posting before/after images, providing resident information, and soliciting feedback.

Source: San Francisco City on OECD Observatory of Public Sector Innovation, 2016, https://oecd-opsi.org/innovations/the-mayors-fix-itteaml.

While many of the challenges and issues identified by the Fix-lt Team may have been regular business (e.g. failures in service issues), it provides a platform for issues to be surfaced, as well as significant data to understand patterns and opportunities for novel responses. It also highlights some of the issues regarding learning:

- Problems can sometimes be explicit (citizens can articulate their concerns) but also sometimes need to be discerned or divined (the problems can be identified through analysis of patterns and behaviours over time)

- Learning needs to be seen as an integral and ongoing part of the job, rather than separate to the job, if it is going to be an effective element of identifying where and how problems are arising

- Learning can be an open process, drawing on a range of sources, allowing for multiple perspectives on the same sets of data (including opinions and lived experiences).

Another case (Box 5.2) provides reinforces some of these considerations.

\section{Box 5.2. Citizen Feedback Dashboard}

Indonesia's Ministry for National Development Planning partnered with the U.N.-affiliated Pulse Lab Jakarta to launch the National Citizen Feedback Dashboard in 2015. The Dashboard visualises citizens' feedback and enables public officials to prioritise trending issues based on enhanced data analysis. The tool combines data from LAPOR!, the national citizen feedback mechanism, with the passive feedback contained within the public discourse on social media sites, such as Twitter. The tool applies volume, category, keyword, location and co-topic analysis to the combined data, resulting in a dashboard visualisation of trends in the feedback from citizens and an early warning alert system drawing attention to surges in complaints on a particular theme or within a certain geographic area. The tool is based within the Centre for Data and Information of the Ministry for National Development Planning of the Government of Indonesia.

In contrast with dealing only with concerns or complaints on a case-by-case basis, which was the previous practice in Indonesia, the Dashboard allows public officials to get a better sense of broader citizen concern trends. The system allows for better 'upstream' policymaking with 'downstream' programme delivery, and thus, better enables the public administration to be more responsive to the evolving needs of society.

Source: Pulse Lab Jakarta and the Observatory of Public Sector Innovation, 2016, What's the problem? Learning to identify and understand the need for innovation. 
By drawing on complaints and feedback, this case demonstrates that single issues can become data points that can be drawn upon to build a bigger picture and richer understanding of what is occurring, opening up potential issues and problems where changed responses are needed, including novel ones. This approach also allows for a sense of issues in regards to the specific (service delivery) as well as broader (policy issues).

A further case (Box 5.3) illustrates how others can be empowered to help express their views about opportunities for change, and to contribute more sophisticated evidence.

\section{Box 5.3. Crowdsourcing alternative policy proposals' impacts on SMEs (small and medium enterprises)}

An innovative web-based tool called SME test enables the public (citizens, business entities, economic and other interest groups) to quantify the impact of their alternative policy proposals on SMEs, in addition to substantiating their comments and proposals on a public policy proposal.

The main functionality of the application is calculation of the costs and benefits of various alternative options to solve the identified policy problem. Although it is essentially based on the Standard Cost Model (SCM) methodology, it enables the identification of qualitative effects of proposed public policies, as well as all others compliance costs such as direct financial costs and costs of additional investments. It is linked to the public records, so users don't need to obtain information on individual parameters required for the calculation of costs and benefits (e.g. population).

In the first step, the user identifies various alternatives to solve the policy problem and assigns to them all the related obligations, that the stakeholders, to whom the regulation refers to, will have to comply with. For each obligation, the user enters the parameters necessary for the calculation, and then the system itself calculates predicted costs or benefits. It is important to note, that a calculation can be made not only for new obligations, but also assessment of impacts of amended or abolished obligations can be made.

The public can thus access the tool, through the eDemocracy portal that enables citizens to actively cooperate and take part in the decision-making process. The most important part in that is the chance to influence the drafting of regulations by expressing opinions and sending proposals and comments on regulation drafts to those who prepare them and to the final decision-makers. The eDemocracy portal allows publishing of documents of regulation that is being created. The interested public (citizens, NGO's, etc.) can, therefore, participate in the regulation drafting process by sending their comments, proposals opinions via the eDemocracy website.

From spring 2018, in addition to submitting a comment, the public can also provide a concrete calculation of the anticipated effects of the proposed policy alternatives.

Source: Slovenia Ministry of Public Administration on OECD Observatory of Public Sector Innovation, 2018, https://oecdopsi.org/innovations/crowdsourcing-alternative-policy-proposals-impacts-on-smes-small-and-medium-enterprises/.

By equipping external actors with the means to articulate their concerns and issues in a way that is more compatible with the policy process, this tool provides a means to expand the pool of people who can help to identify problems, test assumptions, and help to reframe the problem using different perspectives. It also expands the ability of an existing process to uncover alternative perspectives, help make the underlying assumptions explicit, including what exactly different actors are expecting or how they understand the framing of the problem space. 
Through the OECD's analysis, six criteria suggest themselves as being important features in tools and methods (OECD, 2016) if they are to aid learning where and when an innovative response is needed. These include that the tools aid to:

- Clarify intent: The tools help with clarifying what is actually trying to be achieved and, therefore, assist with identifying the gap between what is and what is needed.

- Make assumptions explicit and build shared understanding: The tools help make underlying assumptions and mental models/existing conceptions of the problem explicit, and therefore easier to reflect on and to challenge. This aids with building a shared understanding of the problem, and therefore an increased likelihood that it is agreed upon as a problem requiring an innovative response.

- Avoid jumping to conclusions: The tools encourage a wider exploration of problems. A natural tendency for organisations is to see a problem and act. Learning for innovation emphasises that problems should not be taken at face value, that the relationship between cause and effect may be complex or even unclear. Processes that can allow increased exploration of the nature of the problem before requiring action, investment and the elimination of other options offer a better chance for the problem to be understood.

- Connect with others: The tools involve others connected to the problem and help access or bring to bear their tacit knowledge to the problem being explored. People's lived experience of problems is important but can be hard to articulate in the form of clear needs, relevant insights or explanations.

- Experiment and reduce the cost of failing: The tools emphasise experimentation and testing of aspects of the problem. Processes that reduce the time, effort and cost of experimentation make failure a less significant issue and lead to faster learning about the problem and how to respond.

- Reframe the problem: The tools help reveal alternative ways of looking at the problem. The presentation of problems may sometimes suggest that there is an obvious way of responding, however the complex and interconnected nature of problems mean that care should be taken. Sometimes the best way of responding to a problem will be to rethink the nature of the problem. This act will then suggest new ways of how the problem might best be responded to and what sort of interventions will be most promising.

\section{Generating ideas}

Generating ideas can be a simple process, happening only within a team, or it can occur at a national level, open to everyone. It may be about identifying how to change something small or it may be about something big. One case (Box 5.4) rolled-out at a national level helps to illustrate a number of important elements for teams to consider. 


\section{Box 5.4. Portugal's Participatory Budget process}

The Portugal Participatory Budget (PPB) is a democratic, direct and universal process that allows civil society to decide on public investments in different governmental areas. It is also deliberative, which means that Portuguese people are presenting investment proposals and they choose, through voting, which projects are to be implemented, in a transparent and open way.

To ensure the maximum engagement of citizens from all over the country, the PPB consists of a hybrid participatory model that combines face-to-face interactions between citizens and the State, with the use of ICT tools specifically developed to bring the initiative to all citizens and ensure that everyone can fully participate.

The face to face approach is mainly based on participatory meetings held nationwide, in which the population is able to present and discuss their ideas in person, with the assistance of specialised personnel managing these sessions. Still, the citizens can also submit their proposals at the Citizens Spots (assisted digital services counters) and at some public libraries all around the country. The citizens can use digital tools to participate, but also more traditional channels, so anyone can take part of the initiative, even the ones with fewer digital skills. Anyone can participate, which fosters social inclusion and at the same time enhances trust in the public administration.

The proposals can also be presented online at the PPB portal. In fact, the PPB 2018 portal plays a central role in the implementation of the initiative as it presents three key features: aggregating all the information about the project; allowing citizens to submit their ideas for proposals; and allowing citizens to vote on the final set of proposals (which can also be done through free-of-charge SMS).

The projects can be regional, or national, thus connecting different areas of the country, and encouraging a broader public participation.

The PPB aims to bring people closer to politics and decision-making, compelling them to present sustainable proposals regarding other cities/regions besides their own, fostering an inclusive view of the country. Populations traditionally not heard as they should be, such as the rural communities, have now an open channel to directly participate in the policy making process.

The first edition of the PPB was carried out in 2017 and gathered 1015 ideas (Phase 1 - Collection of citizen's ideas), which resulted in 599 projects to be voted (Phase 2 - Technical analysis of the submitted ideas according to defined rules and criteria), 78815 votes by the Portuguese population (Phase 3 - Voting) and 38 winning projects, to be implemented by the government and by the respective sectorial services of the Public Administration, in discussion with the proponents of the proposals.

Source: OECD Observatory of Public Sector Innovation, 2017, https://oecd-opsi.org/innovations/portugal-participatory-budget/.

The case highlights some important issues:

- The importance of having a clear sense of the appetite for ideas - what sort of ideas are being asked for, of what scope, and what are the parameters of what will be considered?

- The role of framing - in this instance there is a clear sense of how this is a democratic activity seeking inclusive input from citizens, and thus citizens can understand the underlying intent.

- The process has been designed to be a repeatable process - i.e. there is a clear sense of how the ideas will be filtered and chosen from, participants can see their ideas and follow their progress, and are encouraged to participate again. 
- There is a clear sense of why participants may want to contribute and legitimacy underpinning the initiative asking for the ideas - there is also a pre-existing relationship, although potentially weak, between potential participants and the entity (the government) asking for the ideas.

- Participants are supported in their participation - they can contribute via a number of different channels.

- Political ownership - there is a clear sense of the political sponsorship and ownership of the process, and thus certainty that something will result or happen from the process.

There are any number of tools and methods that can assist teams and organisations in taking a more organised and sophisticated approach to finding and filtering ideas. One such example is that of having an explicit idea management system (Box 5.5).

\section{Box 5.5. CSIRO Idea Management System}

The CSIRO, the Australian Commonwealth Scientific and Industrial Research Organisation, introduced an idea management system in 2015 as part of developing a more inclusive innovation approach in an organisation of over 5000 people. Based on the need for a system that could cater to a large number of people, that met security requirements, and that was easy-to-use/integrate with existing systems, a licence for a commercial system was procured for use within the enterprise's IT environment.

The first use of the system was as part of a strategy development process, where four challenges were run, each for a period of two weeks. This was one of the first times within the organisation that people could see what others were saying in an open forum. Over $40 \%$ of staff participated in the process and nearly 700 ideas were submitted, with over 7000 comments made. The process helped ensure that the development of the strategy was well informed by staff views, and that staff felt listened to.

Subsequently the idea management system has been used for a mix of all-staff challenges and for specific issues within particular business areas.

Some of the key factors for making the most of the idea management system included:

- consistent and ongoing communication efforts to set expectations and build engagement

- support for the team managing the idea management system

- a clear sense (by both staff and the organisation) of what would happen when people participated

- enticement and encouragement for people to build on the ideas of others

- topics that connected with the interests, work and culture of staff and the organisation.

Source: OECD, 2017, What's possible? Finding and filtering innovative ideas.

This case highlights the importance of setting clear expectations from all involved; that participation cannot be assumed just because there is an invitation and active engagement strategies are necessary; and that people are more likely to participate if the issues are relevant to their context.

Another, very different, case (Box 5.6) helps to highlight some alternative dimensions of ideas generation. 


\section{Box 5.6. UNDP Positive Deviance Pilot: strategies for enhancing women's public participation in Pakistan's Federally Administered Tribal Areas (FATA)}

Pakistan's Federally Administered Tribal Areas (FATA) is a remote mountainous region in western Pakistan, bordering Afghanistan. Due to decades of conflict and weak governance structures, poverty is pervasive and private and public infrastructure and livelihood opportunities have been limited in the area. In FATA, the prevailing cultural system attaches great importance to the concept of male honour, signifying independence, self-respect, being a provider, and protecting female family members.

This attitude results in very few women in FATA being allowed to engage in employed work or public life and discourse outside the home. In the tribal areas, transgressors of the cultural norms are taunted by the rest of the community members. As such, women rarely engage in paid employment outside the home, or even public life and discourse. UNDP Pakistan projects have struggled to find ways to include women in FATA due to these constraints. Consequently, to design a better targeted and locally relevant programme the UNDP decided to first gain an understanding of the FATA women and their needs by investigating the restrictions on women's engagement in public. It was known that there were women from and in FATA working in public spaces such as hospitals and schools. Therefore, the hypothesis was: if it was possible to understand these few women outliers' strategies to overcome resistance of their families and communities, then it would be possible to design a more effective and sustainable women empowerment programme using locally accepted behaviour change strategies. This approach also provides an insight on issues women face that could be easily missed during traditional project design stages. This innovation not only aimed to benefit the women and their communities but also UNDP in finding more inclusive and impactful ways of designing programming for the very hard-toreach marginalised groups.

With the financial and technical support of the UNDP Global Innovation Facility, a Positive Deviance (PD) approach was used because it combines an ethnographic approach with rapid prototyping. PD has only been used in Pakistan for newborn care by Save the Children. From Save the Children's example, it was felt that PD could be a suitable method to understand sensitive and complex issues through a solution that is participatory. PD is an experiential problem-solving approach based on the premise that in every community there are a few individuals whose uncommon but successful behaviours and strategies enable them to find better solutions to overcoming challenges than their peers, while having access to the same resources. The approach is participatory as it is entirely led by communities identifying indigenous strategies. UNDP entered the communities with a "learning hat"; as listeners; making no assumptions. The identification of "positive outliers" was entirely community-driven. Through interviews and community discussions, we were able to identify how women in tribal areas overcame constraints through the communities perspectives as well as the women themselves. The process of walking in with no assumptions is entirely contradictory to traditional programme design stages but one that we found should be a critical step when it comes to trying to address complex and sensitive development contexts.

The PD methodology itself was a new approach for the Pakistan Country Office. The approach is quick and cost effective, involving an investment of USD 30,000 over nine months. Further benefits of this approach were that it was: i) an inclusive and community-led method that is effective in its targeting; ii) drawing on deep insight into the lives and needs of marginalised individuals - in this case women - on sensitive issues iii) capitalising on solutions that already exist; making the approach more sustainable because of it minimizes resistance as examples are extracted from their community.

The PD pilot provided a solid evidence base from which to further test and scale-up interventions in support of women's engagement in public life in the future. UNDP Pakistan is looking to strengthen women's access to livelihoods and income generating opportunities in the tribal areas, as well as their 
role in governance and public discourse. These findings offer a platform for considering the design of more comprehensive interventions.

Source: UNDP in the OECD Observatory of Public Sector Innovation, 2017, https://oecd-opsi.org/innovations/positive-deviance-pilotstrategies-for-enhancing-womens-public-participation-in-pakistans-federally-administered-tribal-areas-fatal.

This use of positive deviance as a tool highlights some other important dimensions of ideas generation. Sometimes the ideas will already exist in practice, and attention may be best directed to surfacing those and understanding why they are not more widespread, rather than coming up with new ones (hence the importance of finding and filtering ideas). Such a method also helps to challenge assumptions by gaining a greater insight into the lived experience which may conflict with formal understandings of what the issues are. It also gives insight into how ideas may play out in practice, by seeing and appreciating what the hurdles are on the ground.

These cases help to illustrate some of the considerations that public sector organisations and teams should factor in for idea generation.

Six features distinguish tools and methods that are most likely to be of assistance in finding and filtering ideas (OECD, 2017). These include that they:

- Help foster legitimacy: Does the tool aid in fostering legitimacy of the ideas generation process? Does it, by its very nature, assist with establishing that this is an appropriate process being run by the right people?

- Challenge assumptions and better define the problem: Does the tool challenge underlying or explicit assumptions about what might be the best thing to do and help make the understanding of the problem more explicit? Does it help people take a second look at the problem, the issues, the need for change, and really think about what needs to happen?

- Provide new insight into what's possible (including existing solutions): Does the tool help expand the horizon of what might be possible, including identifying any existing solutions that might be already used but not well known? Does it provide insight into new ways of thinking about what could be done?

- Identify and build on ideas (including filtering out poor ideas): Does the tool not only identify new ideas, but work to build on and improve ideas, and identify what might be lower quality ideas?

- Provide insight into how ideas may play out: Does the tool provide an insight into how an idea may play out in reality - how it might be received, how it might work, where there might be potential implementation issues, or 2 nd order impacts?

- Contribute to support and ownership of ideas: Does the tool help build support for ideas and identify how different actors might contribute and possibly take ownership of different aspects of the ideas?

\section{Developing proposals}

Developing proposals - turning options into business cases that can be assessed and acted upon - will necessarily vary depending upon the scope and scale of the project or initiative being proposed. Something that relates to a team's internal processes will need a different proposal to something that relates to a whole of government initiative that needs government sign-off and approval and that will have significant scrutiny.

One case (Box 5.7) highlights some of the issues in developing proposals. 


\section{Box 5.7. Citizens Jury, Compulsory Third Party Insurance, Canberra, Australia}

All cars on Australian roads must have compulsory third party insurance (CTP). In the ACT, this insurance was expensive, coverage limited, and most claims needed to be settled in the courts. A Citizens' Jury and extensive stakeholder engagement process was run to develop and improve the scheme. Over seven months 50 Canberrans worked with a group of stakeholders to design the improved scheme, which the Government committed to implement.

Compulsory Third Party Insurance (CTP) exists in all Australian jurisdictions to provide compensation for people injured or killed when their vehicle is involved in an accident.

The design and implementation of CTP schemes is technically complex (it has to balance premiums, benefits and equity). It involves strong vested interests (influential stakeholders - many with a significant financial stake in the system, and with competing priorities). As an issue, it generally has low community interest, until an accident occurs, insurance is needed or if coverage is prohibitively high. In addition, the cost of the ACT scheme was high and there was considerable confusion about the system.

For all these reasons the CTP 'problem' in the ACT was by no means an easy issue to address.

The ACT Government felt that the best way to solve the problem was to empower the community and to involve community and stakeholders in developing a solution.

As a consequence, a citizens' jury process was designed that had three phases and ran over seven months.

1. A representative group (selected through a random selection process) of everyday residents of the ACT (the CTP Jury) determined what they wanted the objectives of an improved CTP scheme to be (with input from the broader community) and wrote a report outlining their objectives.

2. The stakeholders worked with government, an independent Actuary and Scheme Designer to develop four models that met the objectives the citizens had outlined and were within the parameters set by government.

3. The CTP Jury met again to assess which of the models best met their original objectives and provided their decision to the government.

The Citizens' Jury resulted in a well-developed, community designed insurance model ready for legislative development.

The process had a number of key innovative elements:

1. That ACT Chief Minister and the government committed, at the beginning of the process (before they knew what the community and stakeholders would come up with), to pursue implementation of the model the community chose. In effect, the government was empowering the community completely with the full extent of its own power.

2. Integration of stakeholder and community involvement. The process brought stakeholders and community together in a way that rarely happens. Stakeholders played an important role in helping community to understand the breadth of the issues and helped inform them about the existing scheme. The community used this knowledge, along with the information provided by experts (that they selected) to help them define the type of scheme they wanted - the outcomes they wanted from the scheme and the values that would underpin it. This effectively became the brief for the stakeholders to work with government, a scheme actuary and a scheme designer to develop a range of models which would go back to the community for them to decide which best met their original brief. 
3. Collaborative / Co-design approach undertaken with stakeholders - the way in which stakeholders with polarised positions came together to develop an improved scheme.

4. Started from a blank slate. The government did not propose or suggest a starting point for the conversation. They put a couple of 'parameters' around the work - the most important of which was that the scheme that the community chose could not cost citizens any more than the existing scheme.

5. Broadness of the community involved - it is important to note that all interested people in the ACT were able to contribute to the process and assist the work of the 50 Jurors through a supplementary consultation process.

6. Belief in citizens and stakeholders - the government trusted and respected the skills, knowledge and expertise of the community and the stakeholders alike. The government genuinely valued the input that community and stakeholders could bring and authentically worked to bring a voice to all.

Source: OECD Observatory of Public Sector Innovation, 2018, https://oecd-opsi.org/innovations/citizens-jury-compulsory-third-partyinsurance-canberra-australial.

This case helps to highlight the value of having clarity around the criteria for decision-making, or as is often the case with innovative projects, a sense of how those criteria will be developed, potentially in an iterative fashion.

It also illustrates the importance of having clarity around what other factors might shape the process. Innovative projects may often go in unpredictable directions, and there needs to be a clear sense from decision-makers as to the allowable parameters or limits, so that time and resources are not spent on options that will never be acceptable. In this instance, the government set out a fairly broad mandate (the scheme could not cost citizens more than the existing scheme). In other instances it may be important to be more precise (e.g. if there are political sensitivities, risks and/or clear legal/regulatory or budgetary constraints).

Another highlight of the project is the inclusion of extensive consultation and engagement with relevant parties and parts of the system, to allow for a richer understanding of differing perspectives on the proposals being put forward, and the chance for implementation issues to be raised in advance of proceeding with a decision.

The co-design element is an example of how a good developing proposals element of the lifecycle will also ensure that the implications of different options are understood, and done so in a manner that is understandable to those that will be making the decision. Innovative projects can often bring in new approaches and information that may not be familiar to decision-makers, meaning that they are making decisions about things that they may not fully understand, which will likely cause issues for the rest of the innovation process. Finding ways to make information accessible and relevant to the experience of the decision-makers is therefore crucial.

This example also provides process clarity, which can help to ensure integrity of the development of the options and the final decision. In this case there was community participation and therefore a likely chance of broader community trust that the process would pursue options that would be on behalf of and for the community.

A further case (Box 5.8) helps to illustrate some other elements that are important in the development of proposals, as well as an alternate approach for doing so. 


\section{Box 5.8. Northern Ireland (NI) Public Sector Innovation Lab 'Hack the pain' hackathon}

In 2014, a report was published by the Patient and Client Council ('Painful Truth') which told the stories of 2,500 people in Northern Ireland living with persistent pain. A recurring theme in these user stories was the lack of information they had to self-care and self-manage their condition. In Northern Ireland very little information was available on self-management techniques and having local information by trusted local people was cited as an important part of managing the condition.

With this in mind the Public Sector Innovation Lab took the lead in the event management of a hackathon, branded \#hackthepain. 45 developers, designers, service users, and service providers came to Queen's University, Belfast on Saturday 3 June 2017 for 12 hours of information exchange, design and development of IT solutions, and judging. Judges included commercial, governmental, PHA, PCC and patient representatives and prizes were awarded for the winning solution.

Five teams pitched their digital prototypes to the judges at the end of the day. Three of the five prototypes pitched were deemed to be of real value to people with persistent pain in Northern Ireland. The winning proposition would enable people with pain to develop their own pain profile by tracking symptoms in a diary to share with healthcare professionals and contribute to data collection. A website of trusted Health and Social Care (HSC) information was also pitched and is currently in development with NI Government Digital Transformation Services (DTS). A third pitch came from a Virtual Reality (VR) team who developed a mindfulness app prototype. What was particularly innovative during this hackathon was involving service user and provider groups in all aspects of the process from early user insight workshops, one-to-one patient interviews, surveys, speed networking and involvement in the hackathon judging. All post hackathon projects have also involved development with service users. This process has ensured truly co-designed digital services.

Several digital self-management solutions were developed during the hackathon including a virtual reality app for mindfulness, a pain tracking app and a website of information on pain management techniques. Following the hack a website of information has been developed with Digital Transformation Services (Enterprise Shared Services), as part of a beta campaign on a new government communication website, MyNI. The MyNI platform provided the opportunity to create content which was user friendly and interactive, which could be shared, liked and built upon by service users. Creating connections between users, support groups and other community \& government organisations.

As this was a healthcare project it was also extremely important that all information published on the MyNI site was trusted. Working closely with physiotherapists, pain nurses, consultants and dietitians allowed for content creation which was ethically and clinically approved.

The Lab worked in partnership with over 20 internal and external stakeholders including the Patient and Client Council, Regional Pain Forum, Public Health Agency, Enterprise Shared Services and Navatalk to help create over 24 pieces of content.

Source: Northern Ireland Public Sector Innovation Lab in OECD Observatory of Public Sector Innovation, 2018, https://oecdopsi.org/innovations/hack-the-pain/.

This case demonstrates the value of prototyping, which essentially relates to how different options can be made tangible and meaningful to different audiences. This provides a richer basis on which to assess options, which can be very important for innovative proposals where the initial idea, especially if very novel, may be hard to flesh-out and understand. Prototyping or other means for maturing the idea quickly and at low cost, can be of significant help when choosing between novel options.

The case also emphasises the value of bringing together or otherwise involving relevant audiences in the process can be extremely valuable, and enhance the effectiveness of the process. Convening the different 
audiences with different relevant expertise and experiences (in this instance service providers and service users, as well as developers and designers who could help develop the options) can help flesh out the potential issues, challenges and implications of different options. For an innovative option, which may not be easily communicated or understood because of its novelty, this can be difficult to do through conventional consultation processes, where the underlying assumptions brought to the options may be quite different as there is no shared understanding of what they actually are.

The pitching component of the process also allows for different options to be compared and tested on an equal footing, contributing to the integrity of the decision-making process.

Another case (Box 5.9) helps to illustrate some other considerations for developing proposals, particularly in relation to more emergent innovations, where the ability to spell out or make explicit what is actually going to happen may be even more limited.

\section{Box 5.9. Artificial Intelligence and the 'Bomb-in-a-Box' Scenario: Risk-Based Oversight by Disruptive Technology}

Transport Canada has piloted the use of Artificial Intelligence (AI) to perform risk-based oversight by scanning Pre-loading Advance Cargo Information (PLACl) to identify potential air cargo threats (i.e. "bomb-in-a-box" scenario). By using Al to perform this function, there is potential for Transport Canada to save thousands of hours and conduct risk assessments on all air cargo shipments coming from abroad -- in real-time.

To keep pace with the rapid changes in the transportation sector, Transport Canada must explore using disruptive technologies like artificial intelligence (AI). In "thinking big," Transport Canada set its sights on $\mathrm{Al}$ augmenting every process and procedure within the department, freeing up humans to work on the 'sticky' problems. However, Transport Canada recognised the importance of "starting small" with an ideal use-case that allows for applicable testing. Then, if that case is successful, "scale fast" to other areas of the department and possibly, the whole of the federal government.

In this context, Transport Canada identified a use-case for Al with its Pre-load Air Cargo Targeting (PACT) team that receives approximately 1 million air cargo messages per year. For example, if one employee, working at an unrealistic rate of one message per minute, spent all their time reviewing messages, they wouldn't even have enough time to review $10 \%$ of all messages received in a year.

At the time of the pilot there were very few governments that had dedicated resources to scan air cargo messages for risk before cargo is loaded and of the ones that did, none were known to use Al. When considering the resources responsible for customs and border protection, no country was known to be using $\mathrm{Al}$ in that capacity either.

This use-case represented a true collaborative effort by senior executives from different areas of the department. The PACT team within the Aviation Security area of the department was being directly supported by the Digital Services (IT) area of the department. Transport Canada was also investing effort to renew the way it conducted business, so strong support also came from the Transformation area of the department. Additionally, Transport Canada hired one of Canada's Free Agents to lead the project. To top it off, the department did not have enough Al capability in-house, so it partnered with an outside firm that subcontracted with an award-winning IT firm with expertise in Al.

Through this use-case, Transport Canada attempted to answer two questions:

1. Could Al be used to improve the ability to conduct risk-based oversight?

2. How could effectiveness and efficiency be improved when assessing risk in air cargo shipments? 
To help answer these questions, the pilot proceeded in two steps. In the first step machine learning $(\mathrm{ML})$ was used on a subset of the data and in the second step, natural language processing was used on a different subset of the data.

In the first step, a Transport Canada employee was embedded onsite with the IT firm. Two different ML approaches were taken in working with the subset of data: unsupervised learning and supervised learning. In unsupervised learning, the team blinded themselves to the 'outcome' of the risk assessment applied to the cargo message to try and learn about the relationships between all cargo messages. Then, supervised learning was used, where an attempt was made to learn the relationship between the inputs (cargo messages) and the outcome (i.e. did this cargo message warrant a greater level of risk). In the second step, natural language processing was used on a different subset of data with the goal of being able to automatically tag a cargo message with a risk indicator based on 'free text' fields.

The results from steps one and two were very promising - Al would increase safety and security 15fold, as every single message will be risk-assessed. Additionally, through better use of resources, PACT could use Al to increase capacity, while minimizing the number of people required to do the work.

Source: Transport Canada in OECD Observatory of Public Sector Innovation, 2018, https://oecd-opsi.org/innovations/artificial-intelligenceand-the-bomb-in-a-box-scenario-risk-based-oversight-by-disruptive-technology/.

Where there is a high degree of uncertainty, it is difficult to separate the development of the proposal from the implementation, as it may not be possible to have enough information to propose a formal course of action without 'getting hands dirty' and piloting and testing the proposal. The piloting of the proposal can provide rich intelligence about what actually needs to be considered in a more formal decision-making process for a wider proposal. For a more cutting-edge innovative project, the testing can provide or allow for an essential learning process which allows for the development or creation of the criteria by which the project should be judged. Without this, it may be impossible to fairly assess something that has never been done before in advance of it actually being done.

Five criteria have been thus identified as relevant for considering the contribution of tools and approaches when it comes to developing proposals. These include that they:

- Help establish and articulate parameters and criteria for what makes for a good proposal: Does the tool aid in setting out what will distinguish a good proposal from a non-good one? Does it help give some sense of what a 'bad' proposal, or at least one that will not meet the underlying intent, looks like?

- Help elicit business intelligence that can inform implementation: Does the tool help to elicit insight into what might be encountered throughout the implementation process?

- Surfaces possible implications: Does the tools help highlight possible implications of a proposal, and thus insight into how it might be reacted to, how it might integrate with other existing initiatives, or what it might lead to?

- Makes proposals meaningful/tangible: Does the tool help provide decision makers with a fuller sense of what the innovative project involves?

- Aid comparison of competing options: Does the tool assist with the comparing of differing options?

\section{Implementing projects}

The project implementation stage is crucial for the success of a project, as it is where intent meets reality. As noted, this will not always be discrete from the stage of developing proposals, as implementation can blur with testing and prototyping. Effective project management for innovative initiatives requires an ability 
to ensure ongoing learning through the project implementation as the uncertainties of doing something novel are narrowed down, and then act on that learning on-the-go to ensure that the reality of the project still aligns with the underlying intent or need. A case from the US highlights some of the considerations involved (Box 5.10).

\section{Box 5.10. Project Open Data (United States)}

The White House leverages the code repository and social media platform GitHub to co-ordinate and collaborate with government officials and the public to continually innovate on implementation of the U.S. Open Data Policy through Project Open Data.

Project Open Data is a collection of living policy guidance, code, tools and case studies to help government organisations implement the US Open Data Policy and Data.gov to unlock the potential of government data. The platform has evolved over time as a community resource to facilitate the broader adoption of open data practices in government. Through GitHub, anyone - government employees, contractors, developers or the general public - can view, contribute and communicate through threaded discussions. Resources and staff are dedicated to collaborating and communicating with users, reviewing feedback and revising policy based on feedback as needed and are empowered to make the decisions needed to execute on this role.

In addition, bi-weekly meetings for interested government employees are held, both in person and electronically, on open data and governance topics to discuss formal policy updates as well as to provide an opportunity for informal interaction and knowledge sharing.

Source: https://project-open-data.cio.gov.

The project highlights the value, in an area of ongoing change and learning, of dealing with changing contexts. If a project is dealing with an open-ended issue, then it is important to build in capabilities for ongoing learning. It also demonstrates the value of drawing on multiple perspectives, to help facilitate learning from across the system, and that can inform the implementation.

Another case (Box 5.11) helps to illustrate some other considerations.

\section{Box 5.11. Portugal: LabX as a safe space for experimentation in the heart of Public Administration}

The Experimentation Lab for Public Administration (LabX) was born to be a safe space for experimentation to research, design and experiment innovative solutions to improve public services, focusing them on the needs and expectations of citizens and business. This role allows the Public Administration to move forward to where obvious solutions are not available, controlling costs and risks and learning from successive attempts at improvement. In order to turn experimentation in to the "new normal" in the Public Administration, it was essential that the solutions developed were oriented towards the real needs of citizens and business. The intervention had to involve concrete and exemplifying examples rather than merely rhetorical responses to these needs. When placed at the limits of its intervention capacity, without an infinite budget and without an unlimited team, LabX's option was to place these challenges at the centre of its strategy. In order to overcome these constraints, the option was to work in a network, through collaborations that would privilege liaison with civil society organisations, the research centres of the national scientific system or with the community of entrepreneurs. Experimental mind-set, citizen participation, demonstration of value and networking in 
the innovation ecosystem have thus become the vectors of these last two years of LabX's continuous activity as a team of the Administrative Modernization Agency (AMA).

The development of experimental projects provides an opportunity to research, design and experiment innovative solutions that improve public services. Until the moment, working closely with teams of public servants and manages from the public entities that «owns» the problem at hands, LabX has already 12 projects concluded - and is on the verge of increasing this number. More than the expertise in a given thematic area, the experimental methodology is the energy that nourishes those projects: research to define the right problem before thinking about solutions, without relying on past recipes and without subjecting ourselves to acquired routines; co-creation to ensure that all parties involved are heard and can actively participate in building the solution, tearing down silos within the State and overcoming obstacles to citizen participation; and, finally, experiment in order to test before implementing a solution, accumulating valuable lessons that allow to reduce risks and learn from improvement attempts. The materialization of a living laboratory in a public service will be the maximum exponent of this characteristic approach of LabX: a testing space in which public entities submit, in a real context, their solution proposals to the demands of the citizens' experience, in close collaboration with the strategic partners of the Portuguese scientific system.

As LabX does not intend to have a monopoly on innovation within the Public Administration, but also because changes only become sustainable over time if they are internalized by public entities and their employees, it is important to build a lasting ability to continue this change when our interventions are over. To this end, LabX has developed a series of initiatives aimed at energizing Public Administration, namely the immersive capacitation initiatives focused on the specific challenges of a given experimental project and designed to provide public servants with the instruments, skills and practical knowledge to overcome these challenges. LabX acts as a connector and activator of the Public Administration innovation ecosystem, creating bridges between public entities and the national scientific system, the community of entrepreneurs, civil society organizations and, especially, citizens. From its initiatives, the Network of Innovators stands out, as well as the community of practices to which all public servants can belong, regardless of their entity of belonging and their hierarchical level. The members of this network have at their disposal a constellation of contact points, digital and face-to-face, where they can share knowledge, experience and concrete challenges from the public sector. Through LabXpresso, a bimonthly newsletter, they can find practical results and case studies on innovative projects in the public sector. In OFICINA@ LabX they participate in face-to-face meetings to exchange experiences and share doubts among colleagues from the Public Administration. Thanks to the Toolkit, they access a variety of service design tools adapted to the specific context of our public sector.

An innovation laboratory must remain alert to emerging trends and capable of ensuring its own reinvention. To this end, it is necessary that it acts as a trailblazer of opportunities and threats to public services, exploring areas of intervention, instruments or technologies based on their relevance or impact on citizens and businesses. LabX has pursued this horizon of opportunities through its initiatives on the application of behavioural sciences in public policy, the importance of foresight and future scenarios design methodologies, the interface between humans and machines when dealing with emerging technologies or the use of gamification as a way to change organizational culture.

Source: Government of Portugal.

The case of LabX highlights the value of experimentation in helping to understand the scope of the project, and helps to provide intelligence on how to structure and execute the work of the project or initiative. It reinforces the contributions of mixing diverse insights and expertise, including combining different methodologies which can give fresh insight into the implementation challenges and opportunities. The lab also provides a mechanism for projects to draw upon a cross-government view, helping the later stages of implementation. 
Five criteria were identified to help filter tools and methods that may be of most use in implementing projects (OECD, 2018b). These include that they:

- Help structure and execute work: Much of project implementation is about project management. Does the tool help innovation do the core task of implementation: getting the job done?

- Support the incorporation of diverse insights and expertise: Does the tool help to bring in thoughts, experiences, and lessons that may not have otherwise been possible with the innovation team alone?

- Deal with complex and changing contexts: Does the tool position the innovation team to rapidly adjust or pivot in response to surprises, feedback, or learning new lessons as implementation unfolds?

- Transcend bureaucratic silos: Does the tool help innovators to reach beyond their office and organisation? Does it help ensure the innovation is not relegated to a "pocket" of innovation within government, thus stuck and unable to scale?

- Utility for and adoption by users: Does the tool help innovation teams maintain a user focus, thus facilitating adoption and preventing the innovation from fizzling out?

\section{Evaluating projects}

Evaluating innovative projects is often seen as an exercise in efficiency and effectiveness, but that view can often limit the understanding of the impact of the project. An innovative project is unlikely to run entirely according to plan. Given the uncertainty accompanying any truly innovative initiative, there will be unexpected events and developments, and new things to be learnt that mean the project not only varies from the original intent, but should vary, given what has been discovered throughout the process. Teams and organisations need to be flexible in evaluating projects and must have a variety of methods at their disposal to ensure alignment between the project and desired outcomes is properly captured.

An examination of some different cases helps to highlight the key issues for evaluating innovative projects. 


\section{Box 5.12. Outcome-Based Evaluation to improve services and break siloes: Asker Welfare Lab}

Asker Welfare Lab was a service-delivery innovation which sought to improve the welfare and quality of life of vulnerable populations through an "Investment Team" approach across municipalities in Norway. The lab combined the efforts of relevant municipal services and external partners to create an investment team that treated citizens as co-investors.

Before Asker Welfare Lab, each organisation offered services separately and the siloes approach proved to be difficult to navigate and nobody offered a holistic view around complex problems such as housing and living situations.

By taking a holistic approach around welfare and quality of life, it helped bring together the organisations that were operating in siloes and focused on the outcomes - helping vulnerable populations move to more stable situations and off welfare programmes - rather than the outputs specifically measured by bespoke programmes that were unable to deal with the entirety of the problem.

\section{Figure 5.1. Asker Welfare Lab contributes to an evident improvement of the citizen's situation}

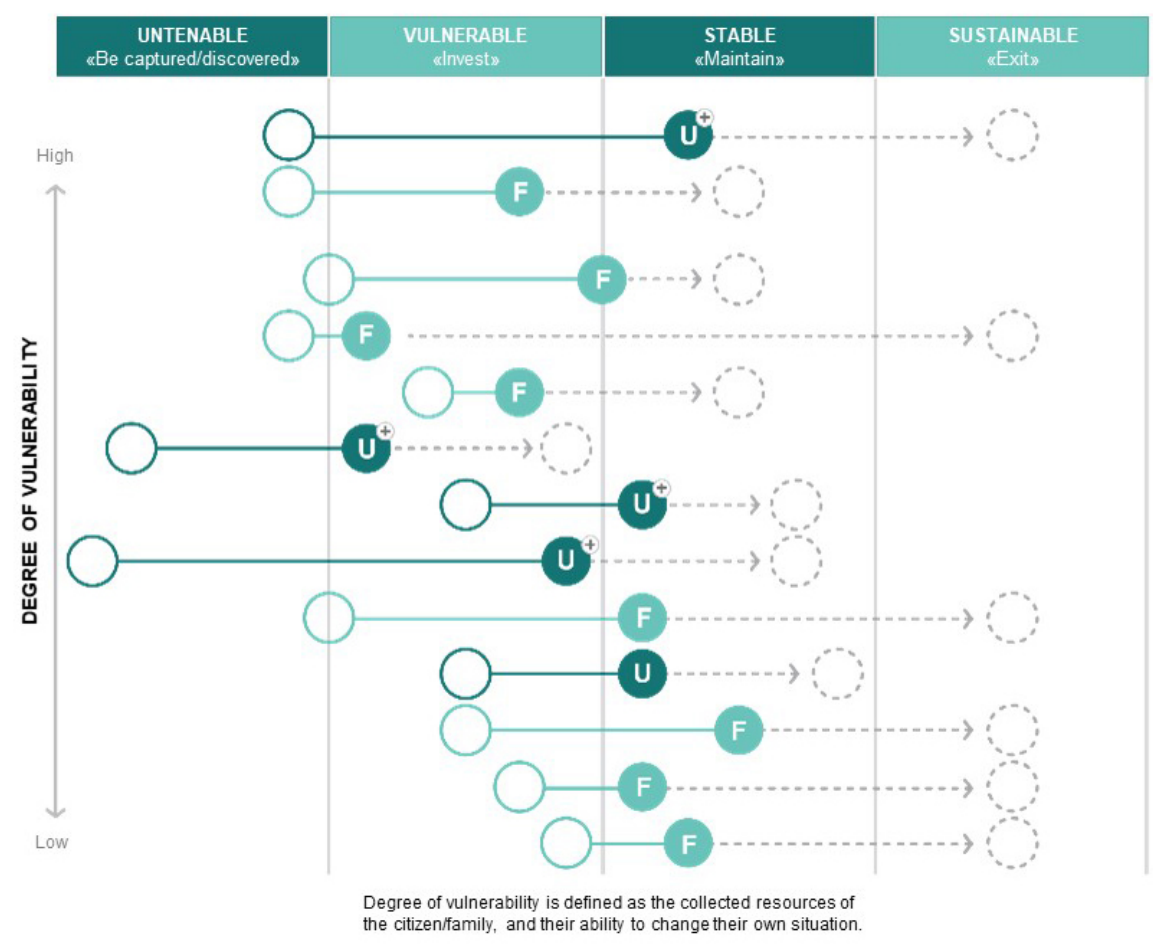

U) Young people
(F) Family
U U $\rightarrow$ Additional investment

Every «line of circles» in the diagram illustrates the «Investment Journey» for a citizen/family that have participated in the pilot. The first circle is their starting point, the second circle shows how the situation has developed over the course of the pilot and the third circle (dotted line) what is the desired goal.

The citizens and families that participated in the Welfare Lab all were in an either untenable or vulnerable situation, and have, already after $\mathbf{8}$ months or less, moved forward in their "Investment Journey".

Through Asker Welfare Lab, it is a realistic estimate that an overwhelming majority of the citizens/families will be in a stable or sustainable situation in the course of 2-3 years.

Source: OECD Embracing Innovation in Government: Global Trends 2018

In this example, Asker Welfare Labs used the "as is" structure and metrics available to show that, although each organisation's activities were efficient and effective, they were not independently reaching the expected outcome. By taking a more holistic approach, Asker Welfare Lab was able to show that a new approach achieved better outcomes. While financial costs and efficiency would need to be considered long term, using an outcome-based approach made space for an innovative idea to thrive. By reframing what was being looked at, by challenging core assumptions and redefining success, the project also helps ensure legitimacy for the initiative - that it is delivering on what is needed rather than against a specific process-oriented output that may be disconnected from what really matters. 
Another case (Box 5.13) helps to highlight evaluation at a broader level.

\section{Box 5.13. The Danish Innovation Barometer}

The Innovation Barometer, developed by Statistics Denmark and The Danish Centre for Studies in Research and Research Policy, seeks to measure public sector innovation in the Danish government in the period 2013-2014.

Innovation in Denmark's public service is defined as "new or significantly improved products, services, processes and organisational structures as well as forms of communication." The survey was rooted in this definition, and conducted according to the Oslo Manual (the international guidelines for innovation statistics).

The evaluation emphasized the barriers and enablers to public sector innovation. Additionally, how workplaces could be conducive environments to innovation practices - for example, tracking the level of investment in innovation projects, and measuring organizational behaviours such as transparency, climate for risk-taking and cooperation.

The survey covered 2363 municipal, regional and state workplaces of all kinds, 1942 of which were considered innovative.

Some of the main highlights were:

- $86 \%$ of all public workplaces have introduced at least one innovation (products, services, processes, organizational structures, forms of communication)

- $74 \%$ of public sector, innovation seek to improved quality of services as an added value

- Employees represent the most important actor when conducting innovation in all government levels: municipal, regional and national

- $79 \%$ of all the innovations carried within the public sector are co-partner with external actors, such as the private sector, non-profits organizations, citizens or other institutions within the public system

- $74 \%$ of the innovative solutions have been inspired by other novel practices and/or cases. This is known as recycled ideas in the Danish context, the fact that civil servants use others contributions and build on them to create new solutions

- A positive correlation was found, between highly educated employees and high levels of innovation

The project encouraged other Nordic countries such as Norway, Sweden, Finland and Iceland to start gathering statistics to measure public sector innovation in their public service.

Source: https://innovationsbarometer.coi.dk/main-results-in-english/.

In this example, Denmark sought to understand where innovation was happening, what motivated it, what form it took, and was the environment within the public sector actively encouraging high levels of continuous innovation. By having this information, it allows a more explicit conversation within individual organisations and the system itself around if the current innovation portfolio is the appropriate risk-balance and size. Identifying barriers and enablers helped to drive new ways of working, as well as giving legitimacy to the innovative activity going on. 
54

A third case (Box 5.14) helps to highlight how evaluation can help to provide insight into impact from the beginnings of a project. 


\section{Box 5.14. Design Thinking and Rapid Impact Evaluation for Public Sector Innovation}

The Employment and Social Development Canada (ESDC) Innovation Lab has pioneered the approach mixing Design Thinking and Rapid Impact Evaluation (RIE) to improve the responsiveness of a programme to user needs and provided lines of evidence for evaluation. The Lab developed a humancentred counterfactual engaging diverse perspectives of stakeholders through multiple workshops, cocreating and stress-testing solutions to current challenges with participants. Early in the pilot, the Lab met end-users in the field with a semi-structured group interview using emotional triggers to garner personal experience. This wide in scope preliminary fieldwork was intended to capture challenges experienced by end-users. The information identified emerging themes that were then substantiated against the current program efforts and translated into a visual graphic recording - effectively summarizing and communicating complex user stories.

The Lab then held two workshops involving 15 and 80 participants respectively. Representation included government stakeholders from across departmental branches, beneficiaries of program funding, failed applicants for funding, front-line providers, end-users, businesses and not-for-profit organizations serving end-users. Participants involved in the design thinking process comprised of diverse communities: women's groups, groups representing ethnic minorities (Indian, Sri Lankan, Somali, Jewish, Chinese, Indigenous, etc.), the LGTBQ community, those with different ability, and covered a breadth in age between 50 to 80 years old - the target age range for the program.

For each workshop, the Lab developed original and tailored collaborative activities precisely engineered to cover gaps revealed in the fieldwork and in-house knowledge-sharing regarding the program. Assumptions were repetitively checked against the five stages of RIE and the five design thinking stages. Both methodologies mixed well. The Lab workshops included a reconsideration of the Theory of Change through problem framing divergence and empathy; considered direct impacts of potential new designed interventions as part of the program design (e.g. emerging ideas for counterfactual scenarios); identified who would be most affected by these new proposed designed interventions, how users would be affected, and on what scale.

The Lab facilitated discussions to explore solutions to current programmatic tensions through gamification and pushed the boundaries of polarity-thinking through back-casting. User empathy was engineered with meta-ethnographic approaches including empathy mapping, persona development based on fieldwork qualitative research and direct interactions with frontline personnel serving endusers in diverse communities. The Lab analysed narrative threads, triangulating and reporting on these insights for the use of the RIE.

A final multi-component counterfactual materialized with the Evaluation Directorate, consultants and the ESDC Innovation Lab discussing findings. Three alternate components to the current program design were proposed: 1) greater internal coordination between program components, 2) an open portal, and 3) greater cross-sector collaboration for new partnerships. From a design thinking perspective, these alternate program scenarios were seeds for prototyping to refine, flesh out and test further. For the RIE methodology, a final workshop hosted program owners and operations (technical advisors), academic researchers (subject-matter experts), and frontline organizations serving seniors who were successful and unsuccessful applicants. At this workshop, participants measured the threepronged counterfactual against a matrix of current program indicators and additional indicators leveraged from user stories garnered during the Lab workshops, and measure impact for the legality, feasibility, and desirability against the current program design.

In the end, two components were retained by the program. The co-development process for developing this three-pronged counterfactual opened a window to provide new evidence to further investigate in a summative evaluation and/or inform immediate programmatic changes. This approach leveraged 
divergent and convergent perspectives to challenge the fundamentals of a program and wedged a space for incremental and more radical innovation exploration.

Source: https://oecd-opsi.org/innovations/design-thinking-and-rapid-impact-evaluation-for-public-sector-innovation/

The case shows how evaluation can be approached from the beginning, creating an early-stage understanding of what impact looks like, and whether it is the desired form of impact.

Five features distinguish tools and methods that are most likely to be of assistance in evaluating innovation projects. These include that they:

- Help foster legitimacy: Does the evaluation criteria properly show expected outcomes and impact? In doing so, it can help others clearly see the goals and ideas for the project.

- Challenge assumptions and redefine success: Does the evaluation make others rethink success and challenge underlying biases? By doing something new, it may require a different understanding of success that also requires a new way of working to succeed. In doing so. Evaluation needs to capture this and serve as a signal for what the innovation is intending.

- Drive new ways of working: Does the tool not only identify new evaluations, but the actions and behaviours needed to succeed?

- Create early-stage understanding of impact: Does the evaluation allow for the team to understand success throughout the project rather than just at the end? Many innovations should have continuous measurement which allow for a decision to both scale or eliminate the project.

- Capture unintended externalities: Attempting something new is likely to have unintended consequences that may not be captured through traditional evaluation methods. Does the tool seek to explore and capture any of these unintended externalities?

\section{Diffusing lessons}

Successful innovative ideas and efforts are not often diffused systematically to other public sector workplaces and remain siloed within the organisations where they were developed. Some innovators fail to realise that their solutions can be usefully applied elsewhere, some lack the means to share their work with a broader audience, and some have no way to discover the innovative work of others

Traditional methods to communicate innovation, such as awards, ceremonies or databases, play a useful role in diffusing ideas, and celebrating and raising awareness about innovation. However, replicating innovations requires changes both to the innovation itself and to the system it will impact. Therefore, the diffusion of innovation is a complex action. Most innovations require adaptation in some form, however there is a lack of information on how to make spreading innovation in the public sector a systematic process.

One case (Box 5.15) gives some insight into how this sort of diffusion of lessons can occur.

\section{Box 5.15. Spreading Innovation -- Denmark}

In order to break down bureaucratic silos and help governments create new ways of working, COI created the Spreading Innovation guide, with the aim of supporting institutions and individuals in the process of replicating innovation in the public sector, and thereby reducing the risks and costs associated with innovation. COI designed the guide in three phases over the course of a year. The 
process involved over 100 people and enjoyed the support of an Advisory Board of handpicked practitioners and researchers.

- In the 1 st phase, a team of researchers carried out a literature review of processes for diffusion of innovation in government.

- In the 2nd phase, the COI conducted field studies in 11 Danish municipalities involved in innovation in the area of welfare technology. Using observation techniques and approaches linked to behavioural economics and "nudge", the COI endeavoured to answer the following question: What happens when institutions spread innovation?

- In the 3rd phase, the main findings were tested in other contexts (e.g. business growth immigration services and child care), across all levels of government (central government, local authorities, hospitals, etc.) and even in non-governmental organisations working on welfare innovation.

The result of the process was Spreading Innovation, a guide deeply anchored in concrete experience and research. It is a tool that supports dialogue between sharers (teams who want to share an innovation) and re-users (teams that want to replicate an innovation). Although any interested sharer/reuser can download and use the guide independently, the $\mathrm{CO}$ firmly believes that personal relationships are essential for innovation and organises networking events to facilitate matching between potential sharers and re-users.

The guide gives an overview of an otherwise complex process. It is structured around six key steps to help government officials share and reuse an innovation (as shown in Appendix IV). For each of these steps, there is a checklist of proposed actions to take and questions in the form of dialogue tools to guide discussions between teams. This approach enables the Spreading Innovation guide to support the spreading of innovations in government, while respecting institutional conditions that may require reinvention or re-contextualisation of some aspects of innovation processes - for example, taking into account the complexities that can exist between municipal, regional and state workplaces.

Sources: $\quad$ http://www.oecd.org/gov/innovative-government/embracing-innovation-in-government.pdf; $\quad$ https:/www.coi.dk/en/what-wedo/spreading-innovation

The case provides an example of a targeted initiative to encourage and to accelerate learning across the Danish public sector about what is possible and what works. It encourages the inter-personal so that people can understand the tacit dimensions of the projects/experiences, giving insight into the preconditions and success factors and how it might adapt to a different context. It helps with the sharing of these lessons, which in turn can lead to new adaptations, and even new projects, that build upon what has gone before.

A second case (Box 5.16) highlights the role other formal mechanisms can play in distilling and capturing learning. 


\section{Box 5.16. Dealing with the triple challenge of sustainability, scale and replication: the Network of Experimentation Labs in Portugal}

LabX's mission is to act as a connector and activator of the Public Administration's innovation ecosystem, creating bridges between public entities, the national scientific system, the entrepreneur community, civil society organizations and citizens. To this end, it has been promoting experimental projects, meetings and co-creation sessions open to these partners. In order to face the challenge of guaranteeing the replicability, sustainability and scalability of its initiatives, LabX considers that projects must not necessarily end with the presentation of a given solution proposal. Ensuring sustainability requires that the skills, techniques and learnings of a project are adopted by the public entities that hosted a given experimental project, ensuring that workers and managers who were involved in the development of a solution can not only manage, but also have the conditions to promote, proactively, other experimental projects in the future. In a sense, LabX wants to ensure that public entities become self-sufficient in innovation and experimentation matters. Enhancing replicability depends, moreover, on the existence of this substrate of competences and attitudes in public entities.

Simultaneously, scaling is critical when dealing with innovation teams, which are either able to insert their methodological approach in public entities, or incur in the risk of having a reduced impact on the whole Public Administration. Given the disproportion of dimensions and, therefore, the permanent threat of overload caused by the eventual entrance of new projects, it was necessary for LabX to exploit the spin-off effects and enhance the irradiation points of innovation within the Public Administration. To that end, LabX promoted the creation of a belt of multipliers, creating or accelerating other teams, units or experimentation laboratories or, if they already existed, connecting them to take advantage of synergies and knowledge sharing between them.

The Experimentation Laboratories Network brings together teams from the Public Administration who are trained and who develop projects with rapid prototyping cycles to materialize the experimentation in their public entities. This is not a private club, but a cross-pollination web between members. Even because these teams intend to demonstrate their value in experimental projects focused on the problems of their entities, they are more than ad hoc creations that demonstrate adherence to rhetorical principles. These teams are agents of multiplication that expose the impact of projects guided by an experimental approach, while delivering value through concrete initiatives adapted to their context.

Source: Government of Portugal

The case illustrates how the diffusion of lessons cannot be taken for granted, and will often require active intervention in order for the lessons to be captured, considered and reflected upon.

To foster the diffusion across the innovation ecosystem, knowledge communities can be linked through effective co-ordination and collaboration networks. Citizen-centred policy and service design rarely sit under one office or institution, but rather at the intersection of traditional policy silos and can cross organisational and sectoral boundaries. A critical component of knowledge management includes mechanisms to link together these different sources of knowledge, which include people, to stimulate learning. Canada's GCpedia and GCconnex (Box 5.17) offer examples of formal mechanisms of how this can be facilitated. 


\section{Box 5.17. Cross-Government Networks to Foster Diffusion (Canada) GCPedia}

The Government of Canada has developed GCpedia, an open source government-wide wiki for collaboration and knowledge sharing. It allows federal employees to share files and post, comment and edit articles placed on GCpedia by their peers. Access is only available to those with a government email address, so third-party collaboration is not possible but, tens of thousands of active users within government demonstrates the significant collaborative power of the platform. The platform helps to break down walls between departments that had been traditionally siloed.

\section{GCconnex}

The government also created GCconnex, an open source government-wide internal-only social media network to enables public servants to connect and collaborate. It is a virtual network where public servants can connect with other public servants with similar interests, or with skills that will help them be more productive in their work. These systems are designed to foster a public sector culture of collaboration and to produce information that is streamlines, relevant, user-driven and integrated.

Source: Government of Canada

The case highlights the value of sharing, of interconnection, and helping aid practitioners with insight into the tacit components of experiences.

Five characteristics distinguish tools and methods that are most likely to be of aid when it comes to the diffusion and scaling of innovative projects. These include that they:

- Identify or highlight what works (and what does not): Diffusing lessons requires the lessons to be linked to something. Does the tool help identify or highlight successful initiatives? Does it provide a locus or a focal point as an entry point to the relevant insights?

- Provide insight into the tacit elements (e.g. necessary preconditions): Innovative projects involve doing new things, and so it will often be hard to codify or formalise all of the relevant lessons for others. Does the tool help provide insight into the tacit elements, such as the necessary preconditions and the contextual factors that mattered?

- Facilitate or encourage interconnections: As many of the tacit elements will come from personal experience, does the tool facilitate or encourage interconnections between those involved with the projects and others seeking to learn from them?

- Help to share and scale: Does the tool help with the sharing of lessons? Does it help provide the building blocks to others to help with scaling of the relevant and most promising lessons?

- Spark adaptation rather than direct copying: Directly copying an innovation from one context to another is inherently fraught, given innovation is about what is new to the context. Does the tool therefore help to spark adaptation, rather than directly trying to translate an innovative initiative from one context, where it may have worked, to another, where there may be differing conditions? 
This chapter provides a short summary of the report and guidance on further resources for teams and organisations. 


\section{A summary}

Innovation matters. It is at the heart of effective government, for it is how governments can respond to changing needs and expectations with novel options. In a fast-changing world, the public sector will soon be mismatched for its context if it does not innovate, leading to a loss of trust and loss of faith in the capability of government to be effective.

As noted in this report, many public sector teams and organisations are aware of and acting on the need for innovation. As the OECD's Observatory of Public Sector Innovation has found with its case study database, there are hundreds of examples of innovative initiatives, where public sector teams and organisations and their partners in society have been introducing real change to the public sector.

However, many cases are isolated - islands of innovation in a sea of business-as-usual activity. This has often sufficed. Governments around the world have adjusted and adapted and been relatively successful in delivering for citizens. As change accelerates and the context for government becomes one of flux, this is unlikely to be an adequate response anymore. Public sector organisations need to build on their innovation successes to make innovation a deliberate process. The alternative is that innovation will only happen during occasional windows of opportunity, leaving outcomes determined more by luck than decision.

The changed context - one of complexity, constant yet unpredictable change, and increased interconnectedness - also means that the innovation process has itself become more complex. Introducing successful, sustainable, and continuous innovation in this environment requires greater sophistication. The context in which it is going to be introduced needs to be understood, the experience and the reality of the actors who are going to engage with it must be appreciated, and evolving methodologies and technologies such as design thinking, futures literacy and digitisation require skill and capability. Simply coming up with a new idea will not do. All of this warrants a more sophisticated and explicit approach to innovation.

Yet even with a more sophisticated approach where innovation is treated as an organised process, organisations and teams will still be faced with uncertainty. Doing something novel to the context does not come with any guarantees except that there is a high likelihood that things will not go as expected. Therefore, organisations and teams can bolster their innovation approach by taking a portfolio approach, where the risks are spread across a number and type of projects. With a portfolio perspective, a single project does not have to be viewed as a win/lose proposition, but rather can be seen as an investment that helps increase learning (and unlearning) about what might work or be suitable.

A portfolio perspective also lends itself to public sector organisations and teams taking an ecosystem perspective. Any single team or organisation is unlikely to be able to undertake a significant range of experiments or tests of innovative approaches, despite the potential need when faced with high uncertainty and a rapidly or dramatically changing context. An ecosystem perspective can assist a team or organisation to better appreciate how other actors can assist, explicitly or otherwise, in learning about potential problems that require an innovative response, finding and filtering ideas, testing and maturing proposals, implementing projects, evaluating outcomes, and diffusing lessons.

An examination of examples from around the world highlights how the lifecycle stages play out in practice. These cases help to illustrate some of the core issues and concerns at each stage of the innovation process, and provide insights about the tools and techniques that might be of most relevance or most appropriate at which stage.

In short, the lifecycle approach provides a framework for teams and organisations to reflect upon their innovation process and how the team/organisation is situated in regards to their strengths and weaknesses at each stage of the innovation process. It can provide a basis for gradually developing and building a more deliberate and sophisticated approach to how they approach innovation. 


\section{Innovation is about what is new to context, and therefore requires a contextual approach}

As defined, innovation is about what is new to a context. Therefore, innovation is always contextual, meaning there can be no hard and fast guidance that will account for all of the variation that different contexts might bring.

This report cannot provide detailed guidance for teams or organisations about what they need or should do. However, it has outlined:

- What shapes the innovation process at the team/organisational level of activity

- How the changed context for the public sector requires a more sophisticated approach to innovation if public sector teams and organisations are going to be effective

- How a multifaceted portfolio approach to innovation can help teams and organisations in their innovation efforts

- Why an appreciation of other actors in the ecosystem is important and can aid the innovation process for teams and organisations.

In combination with this, and drawing on the lifecycle reports (funded under the EC's Horizon 2020 programme), the Observatory of Public Sector Innovation has developed a 'Toolkit Navigator' to assist individuals, teams and organisations in finding and filtering the tools, methods and approaches that might be of assistance to them. The compendium of innovation toolkits provides an abundance of guidance, knowledge and codified expertise about using different tools to achieve innovative outcomes. These can help teams and organisations expand their awareness of what is possible, as well as helping them better match tools and methods to their specific contexts and ambitions.

The Toolkit Navigator is an open resource, and teams and organisations are invited to share their own guidance or experiences with different tools and methods.

\section{A caveat}

This synthesis report examines the team and organisational level of analysis. It does not explore the system level, where the dynamics of innovation can be appreciated across the entire level of the public sector (see for instance OECD, 2019; OECD, 2018f). Nor does it explore the level of the individual, where skills, leadership and motivations matter.

A look at a single layer of analysis is limiting however. An individual leader may be highly innovative, but if they do not understand or appreciate the organisational context and innovation as a process, their ability to make significant change will be limited. An individual organisation may become highly sophisticated in innovation, resulting in significant innovative initiatives that stimulate significant change and lead to better outcomes; however, without changes at a system level, these changes may be easily overturned if the defaults of the system reassert themselves. Equally, system-level change is unlikely to occur without the organisations and teams building up their innovation capability and treating innovation as a systematic process, nor without the efforts of individual leaders (positional and situational) who can make the case for change. For the public sector to continue to be effective in a changing and changeable world, there needs to be a concerted appreciation and effort at all levels - individual, team/organisational and system.

In this regard the OECD Declaration on Public Sector Innovation is an instrument intended to help governments articulate their commitment to a deliberate approach to innovation. However, each government - national, state/regional, and local - will need to have an ongoing reflection and conversation about their ability to consistently and reliably develop, deliver and learn from novel approaches if they are to meet shifting expectations and contexts. The OECD and its Observatory of Public Sector Innovation is intended as a resource to assist government agencies on their ongoing innovation journeys. 


\section{Future directions for research}

The process and act of innovation is about what is new, and therefore innovation will always be evolving and changing, as it will build upon what has happened before. This report provides an overview of some of the OECD's research on public sector innovation, but it is a continually shifting field of study.

One particular question that the OECD has identified as meriting further investigation, is to consider what an innovative organisation really looks like. The lifecycle work has studied innovation through the lens of individual stages of the innovation lifecycle. What does this look like in aggregate - i.e. what can be seen when an organisation has developed an overall sophisticated approach to innovation? What are the possible necessary preconditions or elements that are required for this to occur? These are topics that the OECD hopes to investigate in more depth. 


\section{References}

OECD (2019a), The innovation system of the Public Service of Brazil: An exploration of its past, present and future journey, OECD Publishing, Paris, https://doi.org/10.1787/a1b203de-en.

OECD (2019b), "Declaration on public sector innovation", OECD, Paris, https://legalinstruments.oecd.org/en/instruments/OECD-LEGAL-0450.

OECD (2018a), The innovation system of the Public Service of Canada, OECD Publishing Paris, https://doi.org/10.1787/9789264307735-en.

OECD (2018b), "How do we make it happen? Implementing public sector innovation", Observatory of Public Sector Innovation, https://oecd-opsi.org/wp-content/uploads/2019/05/implementation-with-ECcover-1.pdf.

OECD (2018c), "Evaluating public sector innovation: support or hindrance to innovation?", Observatory of Public Sector Innovation, https://oecd-opsi.org/wp-content/uploads/2019/05/Evaluating-Public-SectorInnovation-Part-5a-of-Lifecycle-Report.pdf.

OECD (2018d), "Measuring public sector innovation: Why, when, how, for whom and where to?", Observatory of Public Sector Innovation, https://oecd-opsi.org/wp-content/uploads/2019/05/MeasuringPublic-Sector-Innovation-Part-5b-of-Lifecycle.pdf.

OECD (2018e), "Transferring and adapting: diffusion of innovation knowledge and lessons", Observatory of Public Sector Innovation, https://oecd-opsi.org/wp-

content/uploads/2019/02/Diffusing Lessons LifecycleReport6 FINAL.pdf.

OECD (2018f), "Developing proposals: Making ideas tangible and actionable", Observatory of Public

Sector Innovation, https://oecd-opsi.org/wp-

content/uploads/2019/02/OECD OPSI LifecycleStudies DevelopingProposals FINAL.pdf.

OECD (2018g), "Public sector innovation facets", Observatory of Public Sector Innovation, https://oecdopsi.org/projects/innovation-facets/.

OECD (2017a), Fostering innovation in the public sector, OECD Publishing, Paris, https://doi.org/10.1787/9789264270879-en.

OECD (2017b), "What's possible? Finding and filtering innovative ideas", Observatory of Public Sector Innovation, https://oecd-opsi.org/wp-content/uploads/2019/04/Lifecycle-Report-Finding-and-filteringideas-part-2.pdf.

OECD (2016), "What's the problem? Learning to identify and understand the need for innovation", Observatory of Public Sector Innovation, https://oecd-opsi.org/our-work/publications/.

OECD (2015), The innovation imperative: Contributing to productivity, growth and well-being, OECD Publishing, Paris, https://doi.org/10.1787/9789264239814-en.

van Oojen, C., Ubaldi, B. and B. Welby (2019), "A data-driven public sector: Enabling the strategic use of data for productive, inclusive and trustworthy governance", OECD Publishing, Paris, https://doi.org/10.1787/19934351. 
Potts, J. (2009), "The innovation deficit in public services: The curious problem of too much efficiency and not enough waste and failure", Innovation: Management, Policy and Practice, Vol. 11/1, e-Content Management, pp.33-43. 